\title{
Two modes of dative and genitive case assignment: Evidence from two stages of Greek
}

\author{
Elena Anagnostopoulou' ${ }^{1}$ Christina Sevdali
}

Received: 23 December 2016 / Accepted: 8 February 2020 / Published online: 16 March 2020

(C) The Author(s) 2020

\begin{abstract}
In this paper, we compare the properties of dative and genitive objects in Classical vs. Modern Greek. Based on the difference in behavior of dative/genitive objects of ditransitives and monadic transitives in the two periods of Greek which correlates with a range of systematic alternations in the case realization of Modern Greek IO arguments depending on the presence and category (DP vs. PP) of lower theme arguments, we argue that there are two distinct modes of dative and genitive objective case assignment: they are either prepositional or dependent (structural) cases, as also proposed by Baker and Vinokurova (2010), and Baker (2015) on the basis of cross-linguistic evidence. If we adopt this proposal a number of important implications follow both for the syntax of Modern Greek genitive indirect objects and for the understanding of the change from Classical to Standard Modern Greek which must be seen as a development from a grammatical system where dative and genitive were lexical/inherent/prepositional cases to a system where genitive is a dependent case assigned to DPs in the sense of Marantz (1991). Interestingly, the development from Classical Greek (CG) to Modern Greek (MG) affected the availability of dative/genitive-nominative alternations in passivization, in the opposite direction of what might be expected, i.e. such alternations were possible in $\mathrm{CG}$ and are no longer possible in MG. Our paper addresses this puzzle and argues that the availability of such alternations is not always a diagnostic tool for detecting whether an indirect object DP bears lexically specified or structural/dependent Case, contra standard practice in the literature.
\end{abstract}

\footnotetext{
C. Sevdali

c.sevdali@ulster.ac.uk

E. Anagnostopoulou anagnostopoulou@uoc.gr

1 University of Crete, Rethymno, Greece

2 Ulster University, Jordanstown, UK
} 
Keywords Dependent Case · Inherent Case - Dative · Genitive · Accusative · Greek $\cdot$ Prepositions $\cdot$ Passivization

\section{Introduction}

This paper contributes an argument from two stages of Greek in favor of the proposal that there are two modes of dative and genitive objective case assignment: ${ }^{1}$ they are either prepositional or dependent cases, as also concluded by Baker and Vinokurova (2010) and Baker (2015) drawing on cross-linguistic evidence. Specifically, we compare the properties of dative and genitive objects in two different periods of Greek. Classical Greek (CG) had morphological dative and morphological genitive case productively marking direct objects (DOs) of monadic transitive verbs and indirect objects (IOs) in ditransitives. The distribution of these cases was subject to idiosyncratic information in transitives, in contrast to accusative case which was more productive and regular, and thematic information in ditransitives where dative was used for goals and genitive for sources and possessors. On the other hand, Standard Modern Greek (SMG) has lost dative case and has retained morphological genitive canonically marking all IOs in ditransitives. Crucially, monadic transitive verbs rarely assign genitive in SMG. The majority of verbs that selected for dative and genitive objects in CG now take accusative objects. This correlates with the fact that SMG has a range of phenomena which show that the genitive case assigned to experiencer, source, possessor, goal and benefactive/malefactive IO arguments is sensitive to the presence and realization of lower theme arguments. Genitive morphology systematically surfaces on the higher IO when the lower theme is a DP bearing nominative or accusative case. When the lower theme is absent, realized as a PP or incorporated, then the IO bears nominative or accusative case. On the standard view of dative and genitive as inherent or lexical cases (Chomsky 1981, 1986; Woolford 2006, i.a.), there is no principled way of characterizing the differences between the two stages of Greek nor the transition from one system to the other. On the other hand, under the theory of dative advocated by Baker and Vinokurova (2010) and Baker (2015), the change from CG to SMG can be seen as a development from a grammatical system where dative and genitive were lexical/inherent cases to a system where genitive is a dependent case in the sense of Marantz (1991). ${ }^{2}$ Under the further hypothesis that lexical/inherent cases have the categorical status of PPs (Rezac 2008; Pesetsky 2013; Baker 2015 among many others), the transition from CG to SMG involves a restructuring from PP-datives and genitives into DPs receiving either genitive or accusative dependent case in different syntactic environments (ditransitives vs. monotransitives). We also compare the conditions regulating dependent accusative assignment in ditransitives of different dialects/languages (SMG, Northern Greek,

\footnotetext{
${ }^{1}$ Throughout the paper we generally use 'Case' for abstract Case in the sense of Chomsky $(1981,1986)$ and Vergnaud (2008) and 'case' for morphological case in the sense of Marantz (1991) and Baker (2015), unless the authors we refer to do otherwise (see e.g. Harley's 1995 Mechanical Case Parameter in (22)). For the glosses, we use the Leipzig glossing rules.

${ }^{2} \mathrm{Cf}$. Polinsky (2016) for an argument along the same lines regarding the diachronic evolution of ergative case from PPs to DPs bearing structural case in a range of languages.
} 
English) and we propose that these languages differ in whether dependent case is assigned to the IO in opposition to a lower DO which, in turn, determines whether the DO or the IO is assigned dependent case in opposition to the external argument (EA). This leads to a novel partial cross-linguistic typology of ditransitives. Intriguingly, the diachronic development from CG to MG also affected the availability of dativenominative (Dat-Nom) and genitive-nominative (Gen-Nom) alternations in passives, which were possible in CG and are no longer licit in MG, offering a new perspective on the understanding of such alternations. Our investigation shows that the availability of Dat-Nom and Gen-Nom alternations does not always qualify as a diagnostic tool for detecting whether an argument bears lexical/inherent or structural Case, contra standard practice in the literature.

The paper is organized as follows. In Sect. 2, we describe the CG and SMG facts which lead us to propose that the two systems are syntactically distinct and that the standard treatment of dative and genitive as inherent Cases is not fine grained enough to handle the differences between the two patterns. In Sect. 3, we present our proposal whereby SMG genitives are best analyzed as dependent cases and CG datives and genitives are best analyzed as inherent cases. We provide novel evidence showing that genitive case on IOs is sensitive to a lower argument in the vP domain in SMG, unlike in CG. In Sect. 4, we investigate the realization of genitive and accusative casemorphology in SMG, Northern Greek (NG) and English ditransitives which shows cross-linguistic variation pointing to a parametrization of dependent case assignment sensitive to a lower argument in the $\mathrm{vP}$ domain. We also investigate the implications of our proposal for the (un-)availability of dative/genitive-nominative alternations in passives in connection to our understanding of inherent/prepositional and dependent case. Finally, in Sect. 5 we conclude.

\section{Two types of dative and genitive: A challenge for an inherent Case approach}

\subsection{Dative and genitive in Classical Greek (CG)}

Classical Greek (CG) is the dialect of Greek spoken in Athens in the 5th and 4th centuries BC. In this language, nouns inflect in five morphological cases: nominative, genitive, dative, accusative and vocative, as illustrated in Table 1.

Table 1 Morphological paradigm of a masculine noun of the second declension in $\mathrm{CG}^{3}$

\begin{tabular}{lll}
\hline & Singular & Plural \\
\hline Nominative & anthrōp-os 'man/human' & anthrōp -oi \\
Vocative & anthrōp -e & anthrōp -oi \\
Accusative & anthrōp -on & anthrōp -ous \\
Genitive & anthrōp -ou & anthrōp -ōn \\
Dative & anthrōp -ōi & anthrōp -ois \\
\hline
\end{tabular}

\footnotetext{
${ }^{3}$ An anonymous reviewer questions our transliteration of the CG examples. This is a complicated issue with a number of possibilities. In our paper we are using standard transliteration of CG and not a phonemic
} 
Nominative case is reserved for subjects of finite clauses. Accusative is the most common case for objects and therefore the verbs selecting it are not listed in grammars. Even though there seem to be some semantic generalizations behind the choice of dative or genitive case (Luraghi 2010:64-67; Anagnostopoulou and Sevdali 2015:451-452), these are nevertheless idiosyncratically determined by particular verbs. $^{4}$ (1) and (2) provide the lists of the verbs selecting for dative and genitive objects, respectively:

\section{VERB CLASSES SELECTING FOR DATIVE DP OBJECTS}

a. Verbs denoting appropriateness ( $\operatorname{armoz} \bar{o}$ 'is appropriate', etc.).

b. Equality/agreement (omoiazō 'resemble', isoumai 'be equal to', etc.).

c. Friendly or adversarial feeling or action (epikourō 'assist', timōrō 'punish', phthonō 'be jealous of', etc.).

d. Persuasion, submission, meeting (peithomai 'trust, obey', epomai 'follow', meignumai 'join', etc.).

e. Complex verbs with the prepositions en- 'in', sun- 'with', epi- 'on', para- 'next to', hupo- 'under', and the adverb omou 'similarly' (omonō̄ 'agree', sun-eimi 'coexist', sun-oikō 'cohabit', sum-prattō 'assist', etc.).

\section{VERB CLASSES SELECTING FOR GENITIVE DP OBJECTS}

a. Memory (mimnēiskomai 'remember', epilanthanomai 'forget', etc.).

b. Beginning/ending (arkhō with the meaning 'begin', pauomai 'finish').

c. Taking care of (epimelomai 'take care of', amelō 'neglect', kataphronō 'look down upon', etc.).

d. Wanting, enjoyment, being part of (epithumō 'want, desire', erō 'love', koinōnō 'have a share of, take part in', etc.).

e. Losing, needing (steromai 'lose', aporō 'wonder', deō/deomai 'need')

f. Feeling/perception (aptomai 'touch', akouō 'listen', etc.).

g. Attempt, success/failure (peirō/peiromai 'try', apotugchanō 'fail', etc.).

h. Ruling ( $\operatorname{arkho}$ with the meaning 'rule, govern', turannō 'be a monarch').

i. Comparison (pleonektō 'exceed', prōteuō 'come first', meionektō 'be worse than', etc.).

transcription, essentially making no claims about the pronunciation of the language but instead seeking to simply represent the written forms with Latin letters. We are following Luraghi (2003) among many others in the conventions that we use, omitting stress since it is irrelevant for us.

${ }^{4} \mathrm{Cf}$. Bortone (2010) who points out, in the context of a thorough discussion of the evolution of prepositional constructions from antiquity to present, that while dative, genitive and accusative retained their independent semantic functions when they occured as complements of prepositions in Homer, that was no longer the case in CG, where dative, genitive and accusative often had no clear semantics when they were used as complements of prepositions, resulting in several idiosyncracies. Bortone's observation also holds for complements of mono-transitive verbs in CG, i.e. some independent semantic functions of genitive, dative and accusative are retained when they are selected by particular verbs, but rather weakly, and there is a lot of idiosyncracy in the classes in (1) and (2). 
As shown in (1) and (2), the choice of dative and genitive objects is determined by specific lexical items, verbs (Vs) or prepositions (Ps). ${ }^{5}$ See in particular (1e) for the latter. A similar observation applies to verbs selecting for two objects, which display four case arrays summarized in (3) and instantiated by the verb classes in (4)-(7): ${ }^{6}$

CASE ARrays in Classical Greek ditransitives (Anagnostopoulou and Sevdali 2015:456)
a. Accusative IO - Accusative DO
b. Dative IO - Accusative DO
c. Genitive IO - Accusative DO
d. Dative IO - Genitive DO

ACCUSATIVE IO - ACCUSATIVE DO

(for example, erōtō tina ti 'ask someone (acc) about something (acc)')

a. Asking, demanding, deprivation, dressing/undressing (erōtō 'ask', apaiteō 'order', endūo 'dress', ekduō 'undress', etc.).

b. Teaching, reminding (didaskō 'teach', hupomimnēiskō 'remind', etc.).

c. Action, reporting, benefit (ōphelō 'benefit', legō 'say', etc.).

DATIVE IO - ACCUSATIVE DO

(for example legō tini $t i$ 'say to someone (dat) something (acc)')

a. Saying, ordering, showing, giving (legō 'say', dēlō 'report', hupischnoumai 'promise', didōmi 'give', komizō 'bring', epistellō 'send', etc.).

b. Equating, mixing (isōleksisō 'equate', eikazō 'gather, presume', meignumi 'mix', etc.).

c. Complex verbs with the prepositions epi- 'on', en- 'in', sun- 'with' (epitassō 'assign/enjoin', epitrepō 'entrust/transfer', energazomai 'create, produce', ksugkhōrō 'give up something for someone', etc.).

(6) Genitive IO - Accus ative DO

(for example, aposterō tinos $t i$ 'deprive someone (gen) of something (acc)')

a. Feeding, filling, emptying (estiō 'feed', plèrō 'fill', kenō 'empty', etc.).

b. Prevent, permit, seizing, depriving (kōluō 'prevent', paū̄ 'stop', apotemnō 'cut off', etc.).

c. Receiving, driving, attraction (lambanō 'receive', etc.).

d. Listening, learning, informing (akoūo 'listen', manthanō 'learn', punthanomai 'be informed', etc.).

\footnotetext{
${ }^{5}$ Most prepositions are homophonous to prefixes in CG as shown in Bortone (2010); but there is another class of less frequent items only surfacing as prepositions, which in the philological tradition are called 'improper prepositions' precisely because they cannot function as prefixes. The generalizations above indicate that these items retain the same case licensing properties in both of these roles: when they head prepositional phrases and when they attach to verbs. As will be seen in Sect. 4.3, this is crucial for understanding the passivizability of datives and genitives in CG.

${ }^{6}$ This is the picture that emerges from traditional grammars followed by Anagnostopoulou and Sevdali (2015). On the basis of a more detailed investigation based on corpora (mainly TLG), Anagnostopoulou et al. (2018) have arrived at a more refined picture of the case arrays in (3) which consist of several subclasses.
} 


\section{DATIVE IO - GENITIVE DO}

(for example, phthonō tini tinos 'envy someone (dat) for something (gen)')

a. Taking part, transmission (metekhō/koinōnō 'take part in', metadidōmi 'transmit').

b. Concession (parakhōrō 'concede', etc.).

c. The verb phthonō 'envy'.

Dative and genitive in the different arrays are subject to some thematic and morphosyntactic generalizations (Anagnostopoulou and Sevdali 2015:457): goals tend to be dative, sources and possessors tend to be genitive, and verbs prefixed by dative assigning prepositions must assign dative to the goal, as shown in $(5 \mathrm{c})$.

\subsection{Genitive in Standard Modern Greek (SMG)}

\subsubsection{The characteristics of the SMG system}

The SMG system is in general characterized by reduction in the inventory of morphological cases available. Nouns inflect in four morphological cases: nominative, genitive, accusative and vocative, illustrated in Table $2 .^{7}$

One of the most salient characteristics distinguishing all dialects of Modern Greek (MG) from CG is the loss of morphological dative (see Humbert 1930; Horrocks 2010 and Luraghi 2003 i.a. on the diachrony of the morphological dative) and its replacement by either genitive or accusative depending on the syntactic environment (ditransitives vs. transitives) and the dialect (Southern Greek vs. Northern Greek). Accusative now surfaces on most objects of transitive verbs in all dialects of MG. The vast majority of the verbs that selected for dative and genitive objects in CG now take accusative objects. This is illustrated in (8) and (9) with sentence pairs from CG and MG including exactly the same verbs:

\section{a. Classical Greek}

Ho Odusse-us ephthon-ēse Palamēed-ei dia sophia-n the Ulysses-NOM envy-3SG.AOR.ACT Palamedes-DAT because wisdom 'Ulysses was jealous of Palamedes because of his wisdom.'

Table 2 Morphological paradigm of a masculine noun of the second declension in SMG

\begin{tabular}{lll}
\hline & Singular & Plural \\
\hline Nominative & anthrop-os 'man/human' & anthrop -i \\
Vocative & anthrop -e & anthrop -i \\
Accusative & anthrop -o & anthrop -us \\
Genitive & anthrop -u & anthrop -on \\
\hline
\end{tabular}

${ }^{7} \mathrm{Cf}$. Mertyris (2014) who argues that genitive is also vulnerable and in the process of being lost in SMG. 
b. Modern Greek

O Odisea-s fthon-ese ton Palamid- $i$

the Ulysses-NOM envy-3SG.AOR.ACT Palamedes-ACC

gia tin sofia tu

because the wisdom his

'Ulysses was jealous of Palamedes because of his wisdom.'
a. Classical Greek
Katapsēphēz-ō
tin-os
condemn-1SG.PRS.ACT someone-GEN
'I condemn someone.'
b. Modern Greek
Katapsifiz-o
kapio-n
condemn/vote against-1SG.PRS. ACT someone- $\boldsymbol{A C C}$
'I vote against someone.'

As far as ditransitives are concerned, MG has a dialect split on the case realization of the IO. NG, i.e. the dialects spoken in Thessaloniki and the northern parts of Greek, has ditransitives where both objects bear accusative morphology (Dimitriadis 1999, Mertyris 2014, i.a. for discussion and references):
a. Edhos-a
ton Petro
ena paghoto
gave-1SG.PST.ACT the Petros.ACC an ice cream.ACC
'I gave Petros an ice cream.'
b. Tha se ftiaks-o ena paghoto
FUT you.CL.ACC make-1SG.ACT an ice cream.ACC
'I will make you an ice cream.'

$N G$

On the other hand, in Central and Southern Greek (e.g. the dialects spoken in Athens, Peloponnese, many of the islands), as well as in Standard Modern Greek (SMG; based on Southern dialects, see Mackridge 1985, 2009), the IO bears genitive and the DO accusative, resulting in the pattern in (11) (Anagnostopoulou 2003; Michelioudakis 2012; Georgala 2012, i.a.):
a. Edhos-a
tu Petr-u
ena paghoto
gave-1SG.PST.ACT the Petros-GEN an ice cream-ACC
'I gave Petros an ice cream.'
b. Tha $s u$ ftiaks-o ena paghoto
FUT you.CL.GEN make-1SG.ACT an ice cream-ACC
'I will make you an ice cream.'

$S M G$

IOs are not allowed to alternate with nominative in MG passives. (12a) is ungrammatical in all dialects. Thus, even though NG ditransitives contain two accusative objects, they cannot be assimilated to English double object constructions which freely permit passivization of the IO, compare (12a) to (12b):
a. *O Petr-os
doth-ike
ena pagoto
the Petros.Nom gave-3SG.NACT an ice cream.ACC
'Petros was given an ice cream.'
All dialects of Greek 
b. Petros was given an ice cream.

English

For most of this paper, we will be concentrating on SMG, returning to NG in Sect. 4.

\subsubsection{SMG vs. CG: Two differences reflecting different systems}

The SMG genitive differs from $\mathrm{CG}$ datives and genitives in two respects:

The first difference concerns the fact that genitive is rarely found on single objects of monadic transitive verbs in SMG, unlike CG, as has already been seen on the basis of examples (8) and (9) above. Very few verbs felt by native speakers to be parts of their productive everyday vocabulary of the, so called, Demotiki register (reflecting the spoken, informal language) assign genitive in SMG. Two such verbs are tilefonao 'call' and milao 'talk' in (13):
Tilefonis-a/milis-a tu Petru
called/talked-1SG.PST the Petros-GEN
'I called Petros/talked to Petros.'

Genitive is also assigned by verbs prefixed by archaic genitive assigning prepositions, like the prefixal preposition iper-('over'-) in (14). These verbs belong to the formal/Katharevusa register, which was introduced in an attempt to revive CG as the official language of the Modern Greek state reintroducing features from CG mainly in written official language and thus leading to registers that do not represent a natural stage in the development of the grammar. ${ }^{8}$
a. O Tsipra-s iper-isxise tu Meimaraki
the Tsipras-NOM prevailed the Meimarakis-GEN
'Tsipras prevailed over Meimarakis.'
b. O Simiti-s iper-aminthike tis politikis tu the Simitis-NOM defended the politics his-GEN
'Simitis defended his policies.'

Even though the verbs in (14) are recognized today as active parts of the SMG vocabulary, they belong to a closed system, similarly to the latinate vocabulary in English. For example, as shown in (15) vs. (16), while genitives are freely allowed to undergo cliticization and clitic doubling in SMG (Anagnostopoulou 2003; Michelioudakis 2012, i.a.), the genitive assigned by archaic prepositions is not allowed to undergo these processes, just as in CG:

$$
\begin{aligned}
& \text { Tu tilefonis-a/milis-a (tu Petr-u) } \\
& \text { him.CL.GEN called/ talked.1sG-PST the Petros-GEN } \\
& \text { 'I called Petros/ talked to Petros.' }
\end{aligned}
$$

\footnotetext{
${ }^{8}$ This movement started in the 18th-19th century and was completely abandoned right after the Greek dictatorship in 1974 see Mackridge $(1985,2009)$ for discussion. The official end of katharevousa came by law in 1976. Relics of the archaic language still survive but are not used productively by "naïve" native speakers. The verbs in example (14) in particular are not even relics of archaic language: they are artificial forms that are the direct result of the katharevousa movement, not found in any of the dialects of Greek (Dionysios Mertyris, p.c.).
} 

*O Tsipra-s tu iper-isxise (tu Meimaraki)
the Tsipras-NOM him.CL.GEN prevailed the Meimarakis-GEN
'Tsipras prevailed over Meimarakis.'

The second difference concerns sensitivity to thematic information in ditransitives. As already mentioned, the choice of dative vs. genitive was related to the theta-roles of IOs in CG, e.g. goals had dative while sources and possessors had genitive case. Since there is no longer a dative-genitive distinction, the genitive has been generalized to all IOs in SMG, regardless of whether they are goals (with 'give'), sources (with 'steal') or beneficiaries (with 'bought'), as is shown in (17a)-(19a). By contrast, the choice of $\mathrm{P}$ in the corresponding prepositional ditransitives is thematically determined, se 'to/in' introduces goals, apo 'from' sources and gia 'for' benefactives, as seen in (17b)-(19b).
a. Edhos-a tis Maria-s to vivlio gave-1SG the Maria-GEN the book-ACC 'I gave Maria the book.'
b. Edhos-a to vivlio $s$-tin Maria gave-1SG the book-ACC to-the Maria 'I gave the book to Maria.'

Goal

a. Ekleps-a tis Maria-s to vivlio Source stole-1SG the Maria-GEN the book-ACC

b. Ekleps-a to vivlio apo tin Maria stole-1SG the book-ACC from the Maria 'I stole the book from Maria.'

\footnotetext{
a. Eftiaks-a tis Maria-s pagoto made-1SG the Maria-GEN ice cream-ACC 'I made Maria ice cream.'

b. Eftiaks-a pagoto gia tin Maria gave-1SG ice cream-ACC for the Maria 'I made ice cream for Maria.'
}

In this paper, we argue that CG and SMG are two distinct systems and we need to pursue an analysis that accounts for their differences. In the next section we turn to previous approaches of SMG genitives and present some preliminary observations why they cannot be maintained.

\subsection{Lexical/inherent Case does not capture the CG vs. SMG differences}

The standard, textbook approach to non-accusative objective case, prototypically dative, but also genitive, ablative, instrumental etc., drawing on Chomsky $(1981,1986)$, is that they are non-structural Cases. They are called 'oblique,' 'lexical' or 'inherent' in the literature, and are accordingly taken to be prepositional, or idiosyncratically assigned by particular verbs or tied to specific theta-roles (see Pesetsky and Torrego 
2011 for a recent overview). In an attempt to clarify the nature of dative, Woolford (2006) argues that it is either lexical or inherent Case: lexical dative is idiosyncratic, lexically-selected by certain verbs or prepositions, whereas inherent dative is more regular, associated with specific $\theta$-positions. On the basis of Woolford's criteria, genitive and dative in CG transitives in (1) and (2) qualify as lexical Cases since they are assigned by particular verbs and prepositions, while genitive and dative in $\mathrm{CG}$ ditransitives in (4)-(7) are inherent Cases, as they are systematically associated with specific thematic roles, such as 'goal,' 'source,' 'possessor.'

A further commonplace assumption is that when a DP does not enter into casealternations in passives, this is so because its Case is lexically or thematically licensed and must therefore be retained throughout the derivation (Chomsky 1981, 1986; Vergnaud 2008; see Bobaljik and Wurmbrand 2008; Pesetsky and Torrego 2011 for overviews and references). By this criterion, the SMG genitive is lexical/inherent Case since it is not allowed to alternate with nominative in passives, as was shown by the ungrammaticality of (12a). In terms of Woolford's classification, SMG must be said to mostly lack lexical genitives, with the few exceptions of the genitive-selecting transitive verbs mentioned above (examples (13), (14)), while it productively has inherent genitive Case associated with the $\theta$-roles goal, beneficiary, source, possessor. Based on the criterion that they do not alternate with nominative in passives, Anagnostopoulou (2003, 2005), Michelioudakis (2012) and Georgala (2012) all analyze SMG IOs as bearing inherent/quirky Case assigned by an applicative head in a structure like (20), in agreement with Woolford (2006):

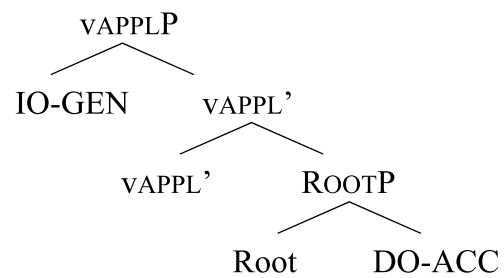

However, if both CG and SMG have inherent dative/genitive Case, then the differences discussed in Sect. 2.2.2 call for an explanation. We argue that genitive and accusative in SMG both qualify as dependent cases which are assigned in opposition to a lower and a higher argument, respectively. On the other hand, datives and genitives in CG were lexical/prepositional cases and were therefore sensitive to thematic/idiosyncratic information. In the following section, we will provide independent evidence that genitive assignment in SMG is sensitive not to a specific theta role borne by a nominal, i.e. the role possessor, experiencer, source or goal, but to the presence of a lower argument in the vP domain. Moreover, there are structural conditions blocking the assignment of dependent genitive case to IO arguments when lower nominals in the same local domain are rendered invisible, exactly as predicted if they bear dependent case (cf. Baker and Bobaljik 2017 for a discussion of dependent ergative case on the basis of similar arguments). We will conclude that the SMG genitive is best analyzed as dependent case, in contrast to dative and genitive case 
in CG which is crucially tied to thematic information and idiosyncratic properties of verbs and prepositions. ${ }^{9}$

\section{Two modes of dative/genitive assignment in two stages of Greek}

\subsection{Our proposal: Dependent genitive in SMG, lexically governed dative and genitive in CG}

In order to account for the systematic and regular distribution of the SMG genitive in ditransitives, as opposed to the idiosyncratic and/or thematically related distribution of CG genitive and dative described in Sect. 2, we will build on Harley (1995) and Baker (2015) who propose to extend to dative case Marantz's (1991) dependent case theory originally proposed for accusative and ergative.

Marantz (1991) argues that the distribution of case morphology is determined by the algorithm in (21) according to which, more specific cases take precedence over less specific ones placed lower in the hierarchy and where the concept of dependent case in (21b) plays a key role for the understanding of case distribution and alternations. $^{10}$

Case realization disjunctive hierarchy (Marantz 1991:24)

a. Lexically governed case (determined by lexical properties of particular items, Vs or Ps)

b. Dependent case (accusative and ergative)

c. Unmarked/environment-sensitive case (nominative or absolutive in the clause; genitive in the noun phrase)

d. Default case (assigned to NPs not otherwise marked for case)

Lexically governed/quirky case (dative, genitive, instrumental, partitive, etc.) is the most specific one, as it is determined by particular lexical items, thus being associated with idiosyncratic or thematic information. Dependent case comes next in the hierarchy as it is more general, determined by the syntactic configuration. Marantz proposes that dependent ergative and accusative case is realized in the clausal domain in opposition to another argument (lower and higher, respectively) not bearing lexical case. Unmarked case comes next, as it only looks at the syntactic environment of nominals, i.e. whether they occur in clauses or DPs. The unmarked case in clauses is taken to be nominative in nominative-accusative languages and absolutive in ergative languages, while the unmarked case in DPs is proposed to be genitive. Finally, default case is realized in environments where no other rule can apply (see Schütze 1997, 2001 for default case).

\footnotetext{
${ }^{9}$ With one important exception, namely passivization, to which we return in Sect. 4.3.

${ }^{10}$ See Zaenen et al. (1985), Yip et al. (1987), Marantz (1991), Harley (1995), Bittner and Hale (1996), McFadden (2004), Preminger (2014), Baker (2015) and others; see Bobaljik (2008:297-302) for an overview. There are differences between different versions of the theories mentioned above concerning where exactly the computation of case subject to the calculus in (21) happens, whether this is PF, Syntax or Spell-Out. The data discussed in this paper are orthogonal to this debate. We thank an anonymous reviewer and the editor for asking this question.
} 
Based mainly on evidence from Icelandic quirky datives which behave like subjects in passives and unaccusatives but retain their case (Zaenen et al. 1985), Marantz (1991) assumes that dative is invariably lexically governed case. Harley (1995), however, points out that there are languages where dative canonically and predictably surfaces on the second argument in the clause only in configurations featuring three arguments. This is the case, for instance, in Japanese make-causatives and ditransitives. She proposes to extend Marantz's dependent case approach to these datives. According to Harley's (1995:161) Mechanical Case Parameter in (22), dative is canonically realized on the second argument checking a structural Case feature in constructions where three arguments are eligible to receive morphological case, in accordance with (22c):

\section{The Mechanical Case Parameter (MCP)}

a) If one case feature is checked structurally in the clause, it is realized as Nominative (mandatory case).

b) If two case features are checked structurally in the clause the second is realized as Accusative.

c) If three case features are checked in the clause, the second is realized as Dative and the third as Accusative.

d) The mandatory case in a multiple case clause is assigned in the top/bottom AgrP.

An alternative definition for dependent dative case has been more recently advocated by Baker and Vinokurova (2010) and Baker (2015). These authors argue that dative in the Turkic language Sakha falls under the rule in (24), a sub-case of the general rule schema in (23) for all dependent cases. ${ }^{11}$ According to (24), the crucial property of dative in Sakha is that it is assigned in opposition to a lower argument in the VP domain, unlike accusative which is assigned in opposition to a higher argument (the external argument, EA) in the IP/CP domain. Note that XP and ZP in (23) and (24) are taken by Baker to be DPs, i.e. according to these rules, dative is only assigned if one DP c-commands another DP inside the VP.

General Dependent Case rule (adapting Marantz 1991) (Baker 2015:79, 111)

If XP bears c-command relationship Y to ZP in local domain WP, then assign case $\mathrm{V}$ to $\mathrm{XP}$.

For Dative: (Baker 2015:131)

If XP c-commands ZP in VP, then assign $\mathrm{U}$ (dative) to XP

Note that ditransitives do not allow us to discriminate between the MCP and the alternative definition in (24) because the two rules make identical predictions for them. If dative is extended to also incorporate morphological objective genitive case in languages where dative has been syncretized with genitive, ${ }^{12}$ then genitive is correctly

\footnotetext{
${ }^{11}$ For Baker, dependent case alongside with case associated with AGREE are the two instances of what was traditionally described as "structural" case.

${ }^{12}$ Note that SMG productively employs morphological genitive case for e.g. possessors in DPs (Alexiadou 2001 and many others). For the purposes of the present paper we wish to remain agnostic on the status
} 
predicted to mark IOs both by the MCP (ditransitives contain three arguments and the second one receives dative) and by (24): genitive will be realized on the higher object in ditransitives but not in transitives containing a single object in the VP, capturing the ditransitive vs. transitive asymmetry observed for SMG. Moreover, in both systems the overall CG pattern and the exceptional SMG constructions in (13)-(14) follow from an analysis of datives and genitives as lexically governed cases subject to (21a). There is, however, a range of environments in SMG where only two arguments are present and genitive is systematically assigned to the higher one, in support of Baker's definition of dependent dative over the MCP alternative. Dyadic unaccusative verbs, for example, psychological predicates corresponding to Italian 'piacere' verbs, as in (25a) (Belletti and Rizzi 1988, i.a., see Anagnostopoulou 1999 for SMG), sensation verbs (see Sect. 3.5 for discussion) and different types of verbs expressing possession/deprivation, as in (25b), productively select for a genitive experiencer or possessor argument and a nominative theme: ${ }^{13}$
a. $\quad T u$ Petr-u
tu
ares-i imusiki
the Petros-GEN him.CL.GEN please-3SG the music-NOM 'Petros likes music.'
b. Tu Petr-u tu xriaz-ete/lip-i
the Petros-GEN him.CL.GEN need-NACT3SG/lack.ACT3SG
enas anaptira-s
a lighter-NOM
'Petros needs/lacks a lighter.'

Evidently, genitive case in (25) cannot be derived from the MCP since these constructions contain two arguments, therefore only two structural case features are checked in the clause. Therefore, it must be analyzed as lexically governed case in Harley's system, which is unsatisfactory as it fails to express the fact that genitive is highly systematic in these environments, just as in ditransitives. On the other hand, defini-

of genitive case in the SMG DP domain. In principle, it could either be environment-sensitive case falling under (21c), as originally suggested by Marantz (1991), or high dependent case assigned to the possessor in opposition to the lower NP argument, as suggested in Baker (2015:167-169) for languages like Shipibo, Burushaski and Nez Perce where ergative is morphologically identical to genitive.

${ }^{13}$ An anonymous reviewer points out that the verb 'xriazome' may also surface with a nominative experiencer/possessor and an accusative theme in examples like (i). The question raised by the reviewer is how we analyze case distribution in constructions like (i).

$$
\begin{aligned}
& \text { O Petr-os xriaz-ete enan anaptira } \\
& \text { the Petros-Nom need-NACT3SG a lighter-ACC } \\
& \text { 'Petros needs a lighter.' }
\end{aligned}
$$

It is important to point out that this type of transitive construction is possible with the verb xriazete and impossible with the verb lipi 'lack' in (25b). In the literature, constructions as in (i) are taken to involve deponent verbs, i.e. verbs with non-Active morphology but transitive syntax. As discussed by Zombolou and Alexiadou (2014) and Grestenberger (2017), among others, many of the Greek deponent verbs are stative experiencer subject psych verbs. A possible analysis for constructions like (i) would be that they involve a root introducing the theme and a stative Voice head introducing the experiencer/possessor and assigning the theta-role Holder to it (Kratzer 1996; Alexiadou et al. 2015; see also fn. 16). The theme receives accusative case in opposition to the higher experiencer argument and the experiencer receives environment-sensitive nominative. 
tion (24) correctly predicts that experiencers/possessors will bear genitive in these constructions, since the VP contains a lower theme object, as depicted in (26). ${ }^{14,15}$

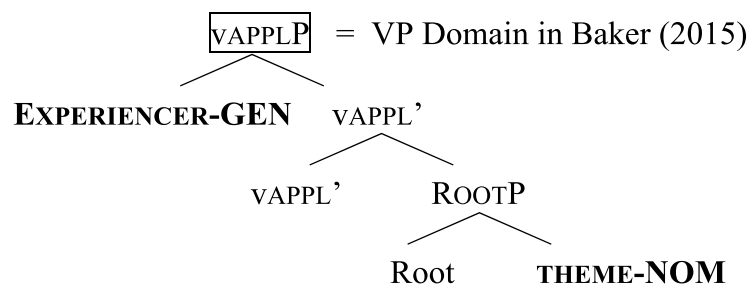

Case assignment in (26) proceeds just as in ditransitives in (27), except that the theme bears nominative morphology since there is no EA in (26), unlike (27) below where an active Voice head introducing an EA DP is present (Alexiadou et al. 2006, 2015; Schäfer 2008, i.a.). More specifically, the theme is assigned dependent accusative downwards in opposition to the higher EA in (27), falling under the standard rule of dependent accusative case. On the other hand, the theme cannot be assigned dependent accusative in the absence of a higher EA in (26), and receives the next lower case in the hierarchy, namely environment-sensitive nominative. The reason why the theme cannot be assigned accusative in opposition to the higher genitive experiencer in (26) is that the experiencer has already valued its case by rule (24), and dependent case is only assigned in opposition to arguments with an unvalued case feature. See Baker (2015) on the details of how dependent accusative and environment-sensitive nominative is assigned to the theme in applicatives, an issue to which we return in Sect. 4.

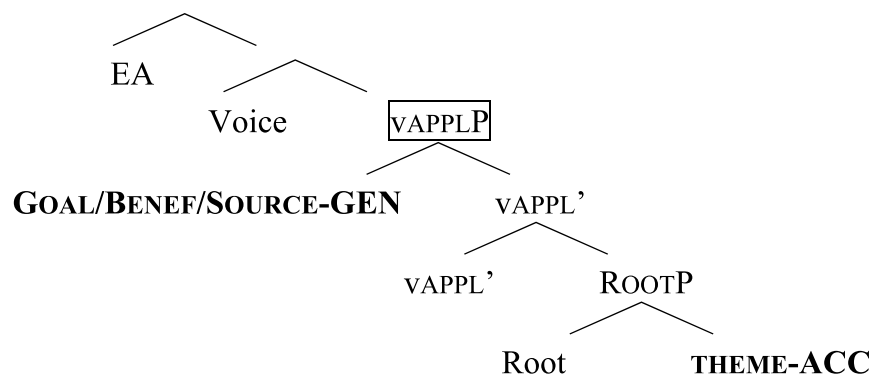

In the next sections, we provide extensive evidence that the distribution of objective genitive case in SMG is indeed sensitive to the presence of a lower DP argument, in support of (24).

\footnotetext{
${ }^{14}$ We are assuming here that experiencers/possessors/goals are introduced by an applicative v which combines with a root introducing the theme argument, but any VP-structure representation would lead to the same result under Baker's definition in (24) above as long as the genitive is higher than the nominative (see Anagnostopoulou 1999 for evidence to this end).

${ }^{15} \mathrm{We}$ are assuming throughout the paper that the theme is an argument of the root. See Harley (2014), Borer (2003, 2005a, 2005b), Lohndal (2014), Alexiadou (2014) and the discussion in the various contributions to Doron (2014) for arguments for and against roots taking arguments. Our account of 'teach' verbs in Sect. 3.9. adopts the view that roots do take arguments.
} 


\subsection{Gen-Nom and Gen-Acc alternations: Experiencers and sources}

If objective genitive case is dependent case subject to the definition in (24), it is predicted not to be assigned to an IO argument when the lower argument is either rendered invisible to the dependent case rule or is absent (cf. Baker and Bobaljik 2017 for diagnosing dependent ergative case along these lines). In this section, we present evidence that this prediction is borne out. We first demonstrate that experiencer arguments show a Gen-Nom alternation depending on whether the lower theme argument is a DP or a PP, and then we show that the case of source arguments (Gen or Acc) is sensitive to whether a lower theme argument is present or not.

Starting from the first set of cases, Greek psychological verbs fall into three types closely corresponding to the Italian 'temere-class' (28a), 'preoccupare-class' (28b) and 'piacere-class' (28c) described and analyzed in Belletti and Rizzi (1988), Pesetsky (1995) and Landau (2010), among many others (Anagnostopoulou 1999): ${ }^{16}$
a. O Jani-s
agapa-i tis kolaki-es
the Janis-Nom love-3SG the flatterings-ACC
'Janis loves flattering words.'
b. I poll-es kolaki-es ton enoxlis-an ton Jani the many flatterings.NOM him.CL.ACC bothered-3SG the Janis-ACC 'Those exaggerating flattering words bothered Janis.'
c. Tu Jani tu ares-un i kolaki-es
the Janis-GEN him.CL.GEN please-3PL the flatterings-NOM
'Janis likes flattering words.'

It is uncontroversial that experiencer object predicates of the 'piacere'-class are unaccusative in SMG and more generally (Anagnostopoulou 1999; Landau 2010). The genitive experiencer in (28c) can thus be safely claimed to be assigned genitive in opposition to the lower DP theme argument, in accordance with the dependent case rule in (24). Crucially, the genitive experiencer argument of 'aresi' in (28c) surfaces as nominative when the lower theme argument is expressed as an obligatory PP. This is shown in (29). In this construction, the verb is marked with Non-Active morphology and is interpreted as reflexive: ${ }^{17}$
O Jani-s
ares-k-ete
*(se kolaki-es)
the Janis-Nom please-NACT-3SG to flatterings-ACC
'Janis is pleased with flattering words.'

\footnotetext{
${ }^{16}$ An anonymous reviewer asks how case is assigned to the experiencer in constructions like (28b) where the experiencer bears accusative case. We do not assume that experiencer object constructions with an accusative experiencer have the same syntax as experiencer object constructions with a genitive experiencer. Following Alexiadou and Anagnostopoulou (2019) we assume that the experiencer in these constructions is not introduced by vAPPL but by the verbal root. The root combines with a causative $\mathrm{v}$ head introducing the causer argument. The experiencer receives dependent accusative case downwards in opposition to the higher causer argument and the causer receives environment-sensitive nominative case. As for experiencer subject constructions in (28a), they have the same syntax as stative verbs more generally. The theme is introduced by the root which combines with a stative Voice head introducing a holder argument (Kratzer 1996). The theme is assigned accusative case in opposition to the higher experiencer and the experiencer receives environment-sensitive nominative case.

${ }^{17}$ We would like to thank an anonymous reviewer for reminding us of the relevance of this alternation. See Alexiadou et al. (2015) for discussion of Non-Active morphology in Greek and references.
} 
Exactly the same type of alternation is illustrated in (30) with the verb 'arki' (is sufficient):
a. Tu Jani
tu
ark-un
ligi
the Janis-GEN him.CL.GEN suffice-3.PL few-NoM.PL
fil-i
friends-NOM.PL
'Few friends are sufficient for Janis.'
b. O Jani-s ark-ite *(se lig-us fil-us)
the Janis-Nom suffice-NACT.3.SG to few-ACC friends-ACC
'Janis is satisfied with a few friends.'

Under the hypothesis that DPs embedded in PPs are rendered invisible to the rules of dependent case assignment (Baker 2015), the case alternations in (28)-(30) provide the first piece of evidence that genitive case assignment in SMG is sensitive to the presence of a lower DP argument. When the lower theme is realized as a PP, rule (24) does not apply and the higher argument surfaces with environment-sensitive nominative. This is similar to ergative languages which show an Erg-Abs alternation in the case of the subject correlating with a DP-PP alternation in the expression of the object and the presence of antipassive morphology on the verb, as exemplified in (31) with data from Chuckchi (Baker and Bobaljik 2017:(16)). ${ }^{18}$
a. ətləg-e qərir-ə-rkən-en
ekək
father-ERG seek-PRES-3SG $>3$ SG son.ABS
'The father is seeking the son.'
b. ətləg- ən ine-lqərir-ə-rkən (akka-gtə)
father-ABS APASS-seek-PRES.3sS son-DAT
'The father is searching (for the son).'

The similarly between the antipassive alternation in (31) and the Gen-Nom alternation in (28)-(30) is not surprising if dative case is dependent case upwards, just like ergative case.

The next set of cases presenting evidence for dependent genitive in SMG involves source ditransitives. As shown in (32a) and (33a), source IO arguments in SMG bear genitive case in the presence of lower theme DPs which are obligatory in the relevant constructions. When themes are absent, then source arguments bear accusative case, as shown in (32b) and (33b).
a. Eklep-san tu Jani *(ton fakelo tis eteria-s) stole-3PL the Janis-GEN the folder-ACC the company-GEN 'Someone stole the company's folder from Janis.'
b. Eklep-san ton Jani stole-3PL the Janis-ACC 'Someone stole something from Janis.'

${ }^{18}$ Unlike (31b) where the oblique argument is optional, the PPs in (29) and (30b) are obligatory. 

a. Listep-san/sufro-san/ksafri-san
tu Jani
$*$ (to robbed-PST.3PL/stole-PST.3PL/stole-PST.3PL the Janis-GEN the portofoli tu) wallet-ACC his-GEN
'Someone stole/robbed Janis's wallet.'
b. Listep-san/ sufro-san/ ksafri-san ton Jani
robbed-PST.3PL stole-PST.3PL /stole-PST.3PL the Janis-ACC 'Someone robbed Janis.'

The theta-role of the single accusative animate object in (32b) and (33b) is identical to the theta-role of the genitive IO in (32a) and (33a). If we assume that genitive source arguments are introduced by applicative heads as in the ditransitive structure (27) above, then the null hypothesis is that accusative source arguments are also introduced by an applicative head, as in tree (34) which lacks the theme DP. ${ }^{19}$ In the absence of a lower DO, rule (24) does not apply, resulting in the assignment of dependent accusative case to the source object, in opposition to the higher external argument (EA in (34)).

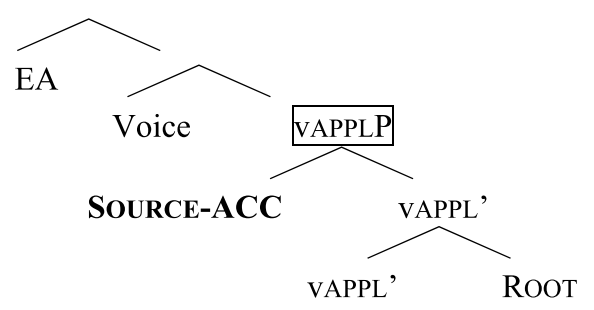

Independent evidence that accusative source objects are indeed introduced by vAPPL comes from the observation that adjectival participles with source externalization in $(35 a) /(36 a)^{20}$ are impossible, in contrast to the well-formed adjectival participles with theme externalization in $(35 b) /(36 b)$.
a. *o klemenos/sufromenos/ksafrismenos fititis the stolen/stolen/stolen student
b. to klemeno/sufromeno/ksafrismeno portofoli the stolen/stolen/stolen wallet
a. *O fititis ine klemenos/ sufromenos/ ksafrismenos this the student is stolen/stolen/stolen
b. To portofoli ine klemeno/ sufromeno/ ksafrismeno the wallet is stolen/stolen/stolen

Even though the source externalization examples conform with Levin and Rappaport's (1986) Sole Complement Generalization according to which adjectival partici-

\footnotetext{
${ }^{19}$ Alternatively, the theme is present but zero and does not count as a case competitor.

${ }^{20}$ On the implausible interpretation of the animate argument as theme, the (a) examples are, of course, possible. We do not include the participle based on listevo 'rob' in (35) and (36) because it does not give rise to morphologically well-formed adjectival participles, i.e. '*?to listemeno aftokinito' (the robbed car) is morphologically ill-formed.
} 
ples are licit only with arguments that are allowed to surface as the sole complements of the corresponding verbs (source arguments surface as sole complements of the verbs in $(32 b) /(33 b))$, they are nevertheless ungrammatical. Following Pesetsky (1995), Marantz (1997), Anagnostopoulou (2001, 2003) and Bruening (2014) we will interpret the ungrammaticality of (35a) and (36a) in terms of the hypothesis that there is a ban against applicative heads in adjectival passives and nominalizations. ${ }^{21}$ In turn, this entails that accusative and genitive source arguments occupy exactly the same structural position in the (a) and (b) examples in (32) and (33). The same contrast obtains in nominalizations, where animate arguments with a source interpretation are ruled out: 22
a. I organomeni klopi/listia ?*tu epixirimatia/ton xrimaton the organized theft/robbery of the businessman/of the money
b. To epitidio ksafrisma/sufroma ?*tu turista/tu portofoliu the skilled theft/theft of the tourist/of the wallet

We conclude that source arguments bearing accusative case occupy the same structural position as their genitive counterparts. Removing the lower theme blocks genitive case assignment to the source argument, as correctly predicted by rule (24). In an alternative analysis where genitive sources have inherent case assigned to them by vAPPLP, the sensitivity of genitive to the presence of the lower theme is unexplained.

\subsection{Gen distribution and Gen-Nom alternations in idioms with Acc clitics}

SMG productively employs accusative clitics that look like expletive, i.e. they lack a denotation, in idioms (see Bibis and Roberge 2004; Leivada and Grohmann 2014; Oikonomou 2011, 2014; Alexiadou 2018). These are either feminine singular as in the examples in (38) or neuter plural, as in the example in (39):

$$
\text { tin patisa her.CL.ACC stepped on-1SG 'I made a bad mistake.' }
$$

(lit. I stepped on her)

tin vrika her.CL.ACC found-1SG 'I got carried away.'

(lit. I found her)

$$
\text { ta' chasa them.CL.ACC.NEUT lost-1SG 'I was startled.' }
$$

(lit. I lost them)

Moreover, the language has a productive process of forming experiencer constructions consisting of a feminine accusative expletive clitic and an eventive verb from different verb classes to which a genitive experiencer is added. The subject is a nominative causer argument bearing nominative case and agreeing with a verb, as in $(40) .^{23}$

\footnotetext{
${ }^{21}$ Bruening (2014) argues that this is not an absolute prohibition. This does not affect the present argument.

${ }^{22}$ Note that $i$ klopillistia tis trapezas/tu spitiu 'the theft/robbery of the bank/the house' is well-formed, suggesting that location arguments are not applied arguments.

${ }^{23}$ There is also an impersonal variant where the causer argument is an optional PP and the verb has 3rd person singular agreement is shown in (i):
} 

a. Ta logi-a su
tu
$*(\operatorname{tin})$
espa-san
tu
the words-NOM yours him.CL.GEN her.CL.ACC broke-PST.3PL the
Jani
Janis-GEN
'Your words annoyed/disturbed/irritated Janis.'
b. I fon-es su tu *(tin) edho-san
the loud voice-NOM yours him.CL.GEN her.CL.ACC gave-PST.3PL
tu Jani
the Janis-GEN
'Your screaming annoyed/disturbed/irritated Janis.'

We propose that the constructions in (40) have a causer subject introduced by a causative $\mathrm{v}$ head attaching above the applicative head that introduces the genitive experiencer. This applicative head attaches above the RootP which contains the verbal root and the accusative pronominal, as schematized in (41). ${ }^{24}$

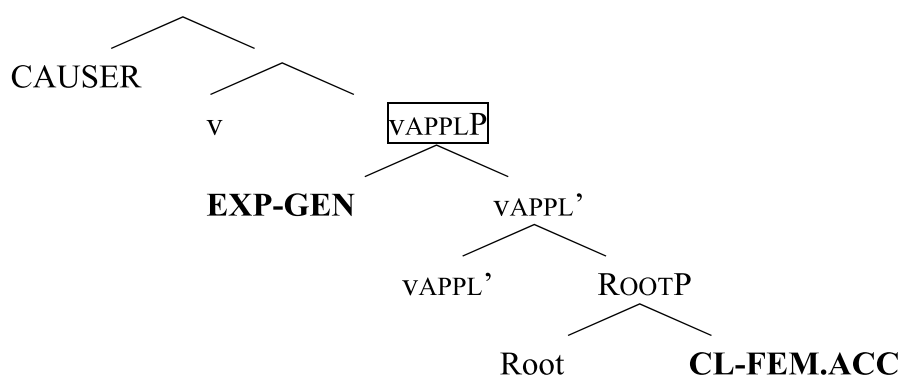

Interestingly, some of the idioms of the type shown in (40) show the alternation in (42) simultaneously affecting the case of the experiencer argument and the lower expletive clitic. Similarly to the experiencer-alternations discussed in the previous section, the experiencer surfaces with nominative case and the verb surfaces with NonActive morphology. Moreover, the feminine expletive clitic obligatorily disappears. The presence of Non-Active morphology which systematically signifies transitivity alternations in SMG (see Alexiadou et al. 2015 for discussion and references) as well
(i)
$*(\operatorname{tin})$
espa-se
(me tis fones su)
the Janis-GEN him.CL.GEN her.CL.ACC broke-PST.3SG with the screams yours
'Janis got annoyed/disturbed/irritated (with your screaming).'

In (i) we are assuming that the null impersonal subject introduced by v counts as a case competitor for dependent accusative case on the clitic. This receives support from the fact that impersonal existential 'have' constructions in Greek also show accusative morphology, i.e. the impersonal null subject in (ii) is clearly a case competitor for dependent accusative assignment to 'many people':

(ii) Ex-i poll-us anthropus ston dromo

has-3SG many-ACC people-ACC in-the street

'There are many people in the street.'

\footnotetext{
${ }^{24}$ Depending on one's theory of clitics, accusative clitics in (40), (41) can be analyzed as DP elements based on intransitive $\mathrm{D}$ heads which then undergo cliticization to T or as forming a chain with a D element in $\mathrm{T}$ as the head of the chain and a DP element in RootP as its tail.
} 
as the fact that the interpretation of the sentences in (42) is identical to that of their active counterparts suggests that the experiencers occupy the same structural position in $(42 a, b)$ and in $(40 a, b)$ :
a. O Jani-s
$(* \operatorname{tin})$
vidho-thike
(me tin simberifora the Janis-Nom her.CL.ACC screwed-NACT.3SG (with the behavior $\mathrm{su})$ yours)
'Janis got annoyed/distrurbed/irritated (with your behavior).'
b. O Jani-s (*tin) spas-tike (me ta logia su) the Janis-Nom her.CL.ACC broke-NACT.3SG (with the words yours) 'Janis got annoyed/disturbed/irritated (with your words).'

As illustrated in (42), a causer argument corresponding to the nominative causer in the examples in (40) may optionally be present, but it has to be expressed as a PP.

This type of idiomatic construction furnishes further evidence that genitive is dependent case in SMG. First, the distribution of genitive in the active crucially depends on the obligatory presence of a lower accusative expletive clitic, in accordance with (24). Second, the experiencer receives nominative case only when the clitic is absent, once again conforming with rule (24).

\subsection{Gen-Acc alternations with affected possessors ${ }^{25}$}

Greek has a possessor raising construction featuring a genitive possessor and an accusative or nominative possessed DP of the type illustrated in (43). Possession is either alienable (as in (43a)) or inalienable (as in (43b) with a body part noun) and the possessor can be expressed as a genitive clitic, as a genitive DP or as a clitic doubled genitive DP, as is always the case with genitive objects in SMG active sentences (Anagnostopoulou 2003). The possessor can be separated by the possessed DP by an adverb, as shown in (43), providing evidence that these are two distinct constituents.
a. O Jani-s
(tis)
katestre-pse
tis Marias
the Janis-Nom (her.CL.GEN) destroyed-Pst.3SG the Maria-GeN
athela-tu to podhilato (tis)
without intent the bicycle.ACC (her)
'Janis unintentionally broke Maria's bicycle.'
b. O Jani-s tis eko-pse (tis Maria-s) xtes
the Janis-Nom her.CL.GEN cut.PST.3SG the Maria-GEN yesterday
ta malia (tis)
the hair (her)
'Janis cut Maria's hair yesterday.'

\footnotetext{
${ }^{25}$ We thank three anonymous reviewers and Julie Legate for raising many issues that led to a complete rewriting of this and the next section
} 
We will follow Deal (2013) who argues on the basis of a comparison between Nez Perce and German that possessor raising constructions cross-linguistically qualify as either raising (in Nez Perce) or control (in German) and develops criteria for distinguishing between the two. In the former type of constructions, possessors are assigned a possessor $\theta$-role inside the DP. In the latter, also called 'external possession constructions,' possessors are simultaneously understood as possessors and beneficiaries/maleficiaries, thus being assigned a more complex $\theta$-role called by Deal and others 'affectee' in their surface DP-external position. Greek qualifies as an external possession language on the basis of Deal's criteria. For example, just as in German (Hole 2005) and unlike Nez Perce, both (44a) with a DP-internal possessor and (44b) with a DP-external possessor are grammatical, but (44b) can only be felicitous if Janis is alive. ${ }^{26}$

Janis died first.....

a. Meta apo ligo pethan-e ke i mitera tu Jani after from a bit died-3SG and the mother-NOM the Janis-GEN 'After a while, Jani's mother died too.'

b. \#Meta apo ligo, tu pethan-e ke i mitera tu after a while, him.CL.GEN died and the mother-NOM his 'After a while, his mother died on him too.'

With a set of verbs involving contact, e.g. touch verbs (e.g. angizo 'touch', filao 'kiss', chaidevo 'stroke/caress', glifo 'lick', gargalao 'tickle'), hit verbs (chtipao 'hit', chastukizo 'slap', klotsao 'kick'), swat verbs (e.g. dhangono 'bite', ghratzounao 'scratch', karfono 'stab', pirovolo 'shoot', tsibao 'peck'), and spank verbs (dherno 'spank', macherono 'knife'), i.e. the Greek translation equivalents of the verbs licensing the body part possessor ascension alternation in English (Levin 1993:71), SMG has an alternation between a construction with a single object noun phrase which contains the genitive possessor of the body part (45a), an external possessor construction in which the possessor has genitive and the possessed body part is expressed as an obligatory DP bearing accusative case (45b), and a construction in which the possessor has accusative case and the possessed body part is expressed as a PP (45c). This PP is optional. As shown by the translations below,

\footnotetext{
${ }^{26}$ An additional criterion for classifying the Greek constructions as external possession constructions might be that a possessive clitic DP-internally is generally optional (see (43)) and with kinship nouns obligatory (see (44)). Given that clitic doubling of possessors is disallowed in SMG (Giusti and Stavrou 2008; Alexiadou 2016; Terzi 2008, 2010), as shown in (i), there is no possible source for the external possessor DP to raise from:
}

$$
\begin{aligned}
& \text { a. I mitera tu } \quad(* \text { tu Jani }) \\
& \text { the mother-NOM him.CL.GEN the.GEN Jani.GEN } \\
& \text { '*His mother/*His mother Jani's.' }
\end{aligned}
$$

Note that Landau (1999:14) argues against the analysis of these clitics as resumptive pronouns because in languages like Hebrew and French they bear genitive case while the raised possessors have dative case, and doubly cased-marked chains are in many languages disallowed. The issue is more involved, however. For example, both Landau (1999) and Deal (2013) draw a distinction between NP-internal possessors and DPpossessors and argue that possessor raising involves raising or control of the DP-possessor. Landau (1999) argues that the obligatory possessive pronoun with kinship nouns is an NP-possessor. If he is right, then this raises the possibility that the clitic in examples like (43), (44) could be analyzed as an NP-possessor. 
English only has the counterpart of (45a) and (45c), and not the counterpart of (45b)):

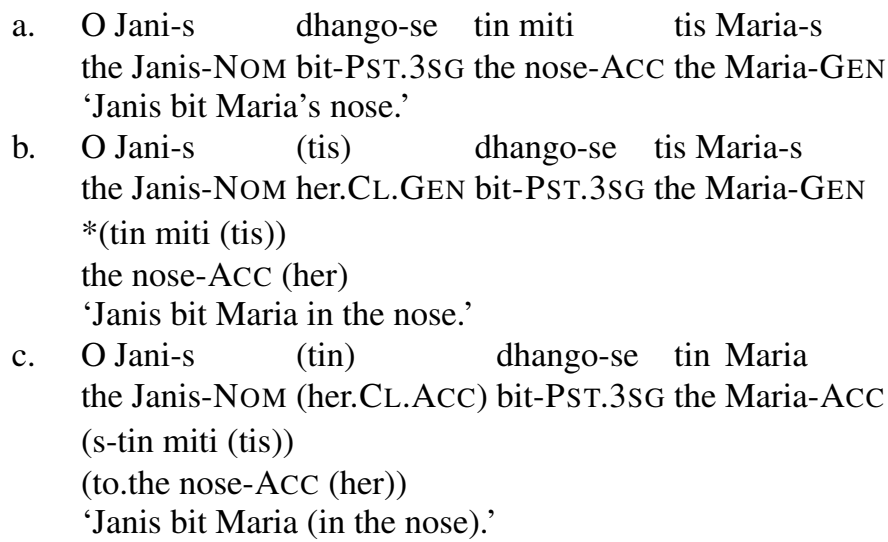

Both (45b) and (45c) show a restriction that reflects affectedness. Consider the examples in (46) which contain the verb skupizo which can either mean 'towel' (remove water from the body or the hair by using a towel) or 'swipe.' When the possessor is inside the DP as in (46a), the sentence is ambiguous. The hair can either be physically attached to the possessor's body (in which case skupizo means 'towel') or it can be on the ground (in which case skupizo means 'swipe'). Crucially, only the former interpretation is available in examples (46b) and (46c) with a genitive and an accusative external possessor, respectively:
a. O komoti-s
skupi-se
ta malli-a
the hairdresser-NoM swiped/toweled-PST.3SG the hair-ACC
tis Maria-s
the Mary-GeN
'The hairdresser swiped/toweled (dried) Maria's hair.'
Ambiguous: Maria's hair is either attached on her or on the ground
b. O komoti-s (tis) skupi-se
the hairdresser-NOM her.CL.GEN \#swiped/dried-PST.3SG
tis Maria-s ta malli-a (tis)
the Maria-GEN the hair-ACC (her)
'The hairdresser dried Maria's hair.'
Unambiguous: Maria's hair is attached to her
c. O komoti-s (tin) skupi-se
The hairdresser-Nom her.CL.ACC \#swiped/dried-PST.3SG
tin Maria s-ta malli-a (tis)
the Maria-ACC on the hair-ACC (her)
'The hairdresser dried Maria's hair.'
Unambiguous: Maria's hair is attached to her

Note that in Nez Perce, where raised possessors lack the affectee role, possessor raising takes place regardless of whether the body part is attached to the possessor or not (Deal 2013:408, discussion of example (41)), in contrast to Greek (46b) and (46c). 
If we assume that the possessor/affectee $\theta$-role is assigned by a designated applicative head in external possessor constructions, then it seems justified to propose that genitive and accusative possessors occupy the same structural position in examples (45)-(46), as depicted in (47).

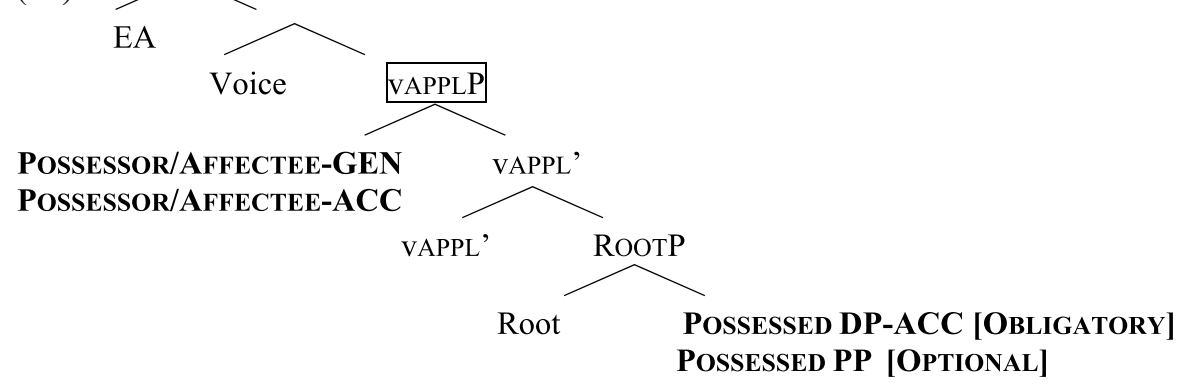

Their genitive vs. accusative case difference can then be linked to the dependent case rule (24). In the (45b, 46b) examples, the possessor receives dependent genitive in opposition to the lower DP. On the other hand, in the $(45 \mathrm{c}, 46 \mathrm{c})$ examples the dependent genitive rule does not apply because the possessed body part is either expressed in a PP or is absent. Therefore, the possessor receives dependent accusative case in opposition to the higher external argument.

Notice that adjectival passives like 'i filimeni gineka' (the kissed woman) are considerably worse than 'to filimeno stoma' (the kissed mouth), providing independent support for the claim that animate affectees are introduced by an applicative head, even when they surface as single objects of these verbs. In a similar manner, event nominalizations like 'to pathiasmeno filima tis ginekas' (the passionate kissing of the woman) lack an interpretation where the woman is kissed (if anything, the woman is interpreted as an actor).

If the above line of reasoning is correct, then the systematic Gen-Acc alternation in the case of affected possessors depending on whether lower body part expressions are present or absent and DPs or PPs provides further evidence for dependent genitive in SMG. Two additional comparative considerations reinforce this conclusion. First, German also has a Dat-Gen alternation with verbs like 'bite,' 'kiss' and 'caress,' as shown in (48). However, the German alternation is insensitive to the realization of the lower argument (see Lee-Schoenfeld 2012 for discussion and references). Importantly, in all of the examples in (48) below, the lower argument is a PP, regardless of whether the higher possessor has accusative case, dative case or both.

\footnotetext{
a. Der Junge hat ihn/ihm in die Nase gebissen. the boy has him-ACC/-DAT in the nose bitten 'The boy bit him in the nose.'

b. Der Mann has sie/?*ihr auf den Mund geküsst. the man has her-ACC/?*DAT on the mouth kissed 'The man kissed her on the mouth.'

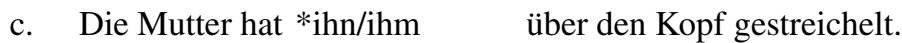
the mother has him-*ACC/DAT over the head stroked 'The mother stroked him over the head.'
} 
Second, Hebrew allows dative possessors in the presence of lower PP arguments, similarly to German and unlike SMG. While SMG genitive possessor raising constructions pattern with their Hebrew counterparts when the lower possessed argument is a DP (in both languages, an affected external possessor is licit-provided that additional 'affectedness' conditions are met-when the possessed DP is an object of a transitive verb or an argument of an unaccusative verb, see Landau 1999 for discussion of Hebrew and references), SMG sharply differs from Hebrew when the possessed argument is contained within a PP. In Hebrew this is possible, ${ }^{27}$ while in Greek this is completely impossible. Witness the following contrasts (Hebrew data from Landau 1999:17-18):

a. Gil yašav le-Rina ba-mitbax

Gil sat to-Rina in-the-kitchen

'Gil sat in Rina's kitchen.'

b. *O Jani-s (tis) kathi-se tis Maria-s

the Janis-Nom her.CL.GEN sat-PST.3SG the Maria-GEN

s-tin kuzina ${ }^{28}$

in-the kitchen

Intended: 'Janis sat in Maria's kitchen.'

a. Gil hitkaleax le-Rina im ha-sabon

Gil bathed to-Rina with the-soap

'Gil took a shower with Rina's soap.'

b. *O Jani-s (tis) pli-thike/baniari-stike

the Janis-NOM her.CL.GEN washed/took a shower-NACT.PST.3SG

tis Maria-s me to sapuni ${ }^{29}$

the Maria-GEN with the soap

Intended: 'Janis took a shower with Maria's soap.'

${ }^{27}$ As discussed in Landau (1999) possessor raising in Hebrew is possible with argumental locative, source and instrumental PPs and impossible with adjunct PPs. Landau takes this contrast to be an argument for possessor raising as movement.

28 (49b) is completely ruled out on a reading in which Mary is the possessor of the kitchen, which is the reading we are interested in here. It seems to us to also be ruled out with a full DP or clitic doubling on any reading in the literal meaning of 'sit.' A variant of (49b) is possible without a PP. The verb 'sit' receives an idiomatic interpretation according to which, Janis resists Mary sexually:
O Jani-s
dhen (tis)
kathi-se
tis Maria-s
the Janis-Nom not her.CL.GEN sat-PST.3SG the Maria-GEN
'Janis resisted Maria (sexually).'

(49b) is also possible with an undoubled clitic that is not interpreted as a possessor of the kitchen. This is probably an 'ethical dative,' subject to very different conditions than the ones discussed here (ethical datives resist doubling, tend to be first person and are licensed under special discourse conditions).
Pigh-e kai mu/tis
kathi-se/katsiko-thike s-tin kuzina ke dhen kun-iotane went-3SG and me.CL.GEN/her.CL.GEN sat/goated (idiom) in-the kitchen and not moved 'He went and sat in the kitchen on me/her and did not move.'

${ }^{29}$ As in (49b), the relevant reading here is one in which Mary is construed as the possessor of the soap. An interpretation of Mary as a beneficiary/maleficiary of Jani's shower is not ruled out by (24) since 
These cross-linguistic differences receive a straightforward explanation if the SMG genitive is dependent case falling under (24), while German and Hebrew datives are inherent cases, and therefore insensitive to whether a lower DP or PP is present in their domain.

Notice that, from the perspective of dependent case, the possessor in ill-formed SMG (49b) and (50b) might be expected to surface with accusative, showing a GenAcc alternation comparable to the one in (45) and (46). This is not possible, however. Genitive possessor raising in SMG is more readily available than accusative possessor raising, the latter being limited to verbs involving contact. The precise conditions under which affectee and possessed arguments are licensed in SMG are highly complex and subject to several idiosyncracies that are poorly understood. This also seems to hold in English (Levin 1993, 2006), and cross-linguistically (Levin 2012). Regardless of this, it is striking and significant that all patterns found in SMG always conform with (24): affected possessors bear genitive when lower possessed arguments surface as DPs, while they bear accusative or nominative in the absence of lower arguments or when these surface as PPs. This is not the case in languages with an inherent dative like German and Hebrew.

\subsection{Gen-Nom alternations with affected possessors/experiencers}

The analysis pursued in the previous section can be extended to examples like (51), (52) which show that genitive alternates with nominative in the absence of a body part argument or when the body part is expressed as a PP with sensation verbs like 'hurt,' 'be cold' etc.
a. Tu Jani tu pona-i *(o lemo-s (tu))
the Janis-GEN him.CL.GEN hurt-3SG the throat-NOM (his)
'Janis has a sore throat.'
b. O Jani-s pona-i s-ton lemo (tu)
the Janis-NOM hurt-3SG to-the throat (his)
'Janis has a sore throat.' (lit: Janis hurts in the area of his neck)
c. O Jani-s pona-i
the Janis-NOM hurt-3SG
'Janis hurts.'
a. Tu Jani tu krio-san *(ta cheri-a (tu))
the Janis-GEN him.CL.GEN are cold-PST.3PL the hands-NOM (his) 'Janis's hands got cold.'
b. O Jani-s krio-ni s-ta cheri-a (tu)
the Janis-NOM is cold-3SG to-the hands (his)
'Janis's hands are cold. (lit: Janis is cold in the area of his hands)
c. O Jani-s krio-ni
the Janis-NOM is cold-3SG
'Janis is cold.'

\footnotetext{
the example is presumably unaccusative, see Sect. 3.7 for discussion. However, we do not find such an interpretation of (50) acceptable.
} 
According to the analysis pursued so far, the affected possessor receives dependent genitive in opposition to the lower vP-internal DPs o lemos 'the throat' in (51a) and ta cheria 'the hands' in (52a). On the other hand, the body parts are contained in a PP in (51b) and (52b). Rule (24) does not apply and the possessor receives environmentsensitive nominative. We can extend this line of approach to the experiencers in (51c) and (52c) and treat them as the single arguments of the Root+vAPPL complex, as depicted in (53). They receive unmarked/environment-sensitive Nom since dependent genitive cannot be assigned, because there is no lower argument for it to be assigned case in opposition to.

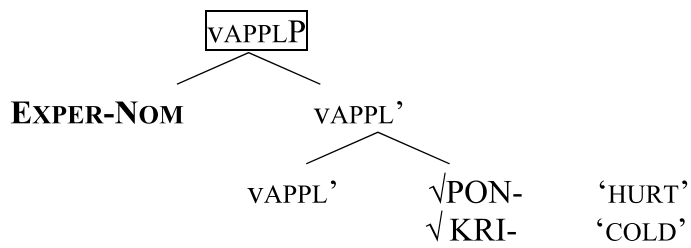

This may also explain why monadic sensation predicates always select for nominative and never for genitive experiencers in SMG. Crucially, genitive can never appear as the sole argument of monadic predicates in SMG, as shown in (54) with "be hungry," "be thirsty," "suffer" and "be anxious":

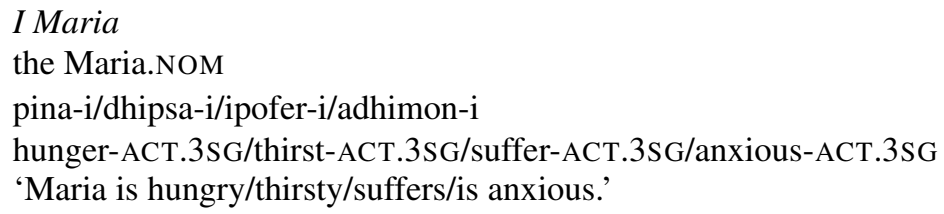

We have compiled a (non exhaustive) list of 83 SMG sensation verbs and 270 psych verbs (a total of 353 verbs) based on the traditional Greek Dictionary 'Antilexicon' (Vostantzoglou 1986 edition) which organizes the Greek vocabulary on the basis of semantic fields (its logic is similar to Levin's 1993 organization of verb-classes in the second part of her book, but Antilexicon is not limited to verbs and is based on a pre-theoretical organization of categories). ${ }^{30}$ Strikingly, we have found not a single monadic verb selecting for a genitive (or accusative) experiencer. In our list, 28 out of 83 sensation verbs are monadic non-alternating, and 66 out of 270 psych verbs are monadic non-alternating, a total of 94 monadic verbs. Their single argument is always nominative, in contrast to languages like Icelandic and German which do have monadic verbs selecting for dative arguments. This is expected if genitive is dependent case in SMG and is unexpected if genitive is inherent case. Some of the verbs we have identified are listed in (55) and (56):

Some SMG monadic sensation verbs

dhipsao 'be thirsty', pinao 'be hungry', krevatonome 'fall sick', turtutizo

\footnotetext{
${ }^{30}$ We did this search in order to answer a question concerning the number of monadic sensation/experiencer verbs with nominative case in SMG raised to us by the editor. Since Greek doesn't have electronic resources that would allow us to perform the relevant counts easily, we resorted to the traditional Antilexicon. Therefore, our list of verbs is non-exhaustive.
} 
'shiver/ tremble', ganiazo 'be very thirsty/tired', ipotropiazo 'deteriorate in health', anarono 'recover', noso, astheno 'be sick', seliniazome 'have an (epileptic) fit', idhrokopo 'sweat', asthmeno 'breathe heavily', lachaniazo 'get out of breath', ighieno 'be healthy', kilopono 'be in labor', ponokefaliazo 'get a headache/suffer from a headache', sinachonome, plevritonome 'get a cold', lipothimo 'faint', righo 'shiver, tremble', choleno 'limp/be amiss/make no progress', pascho, ipofero 'suffer', spartaro, sfadhazo 'writhe (with pain)', kerono, marmarono, petrono 'become petrified' (lit. unmovable like wax, marble, stone), paniazo 'become very pale', korono 'become very hot'.

(56) Some SMG monadic psych verbs

kardhiochtipo 'be anxious/ nervous/ in love', sparazo, plantazo 'be heartbroken, anguished, in deep pain', adhimono 'be anxious/restless', kseniazo 'be/become relieved/free from care', katalaghiazo 'calm down', paraferome 'lose one's temper', ksechnieme 'forget oneself/lose oneself', vrazo, afrizo 'be extremely angry (lit. boiled, steamed)', maniazo 'infuriate, enrage', skiliazo 'infuriate', dhisforo, dhisanasxeto 'be displeased/ dissatisfied', ksespathono 'stand up for', ksespao 'outburst', aisiodhokso 'be optimistic', apaisiodhokso 'be pessimistic', anaskirto 'start, leap', frito 'be horrified', pascho, ipofero 'suffer', stenazo 'sigh, suffer', eksanistame, dhiamartirome 'protest', xerome 'be happy', evdhemono 'live in happiness', dhisticho 'live in unhappiness', ksefantono, glento, glendokopo 'have a good time, enjoy', kamarono 'be proud of'.

Compare to Icelandic (Sigurðsson 2004, i.a.) where e.g. "be cold," "get better" and "be nauseated" select for a single dative argument, and "be thirsty" and "suspect" select for an accusative argument.

Turning back to the Gen-Nom alternating examples we started with, the pattern in (51) and (52) is extremely pervasive and robust in SMG. From our list of 83 sensation verbs, for example, 31 verbs show this pattern, among them paghono, ksepagiazo 'freeze', zestenome 'be/get warm, anavo 'be/get hot', mudhiazo 'become numb', paralio 'paralyze', prizome 'swell', fouskono 'swell/inflate', kriologo 'get a cold', matono 'bleed', vrachniazo 'get hoarse', anakatevome 'get nauseated', tremo 'shiver/tremble'.

An anonymous NLLT reviewer points out that the patterns discussed in this section do not necessarily provide evidence that genitive arguments in SMG are assigned dependent case. An alternative possibility would be that the projection of VAPPL is sensitive to the presence of another NP. That is, the vAPPL introducing affected possessors can only merge with a VP that takes a DP-object. This would explain why the possessed argument is obligatory in examples like (51a) and (52a). In this alternative analysis, affected possessors with nominative case occupy a different structural position than those bearing genitive case. If genitive is (inherent) case assigned by vAPPL, then vAPPL cannot be assumed to introduce an argument that is not assigned genitive. $^{31}$

${ }^{31}$ Note that, if we follow this line of reasoning, then the Gen-Acc alternations discussed in the preceding section, like (45), are not genuine case alternations either. Under the assumption that vAPPL assigns inher- 
If we stipulate that the applicative head introducing possessors can only merge with a VP that contains a DP-object in SMG, as suggested by the reviewer, then this alternative analysis comes close to the dependent case approach to genitive case assignment while maintaining the view that vAPPL assigns inherent case. For the cases under discussion, the two analyses look like notational variants. As pointed out by Baker and Bobaljik (2017:fn. 10) who critically discuss a version of this analysis for ergative case as inherent case supplemented by a transitivity condition, this line of approach essentially builds a version of the dependent case theory into the lexical entries of $\mathrm{v}$ heads.

Even so, the analysis suggested by the reviewer lacks generality in that it cannot capture all SMG data discussed so far. It cannot be extended to the alternation affecting genitive experiencers with the verbs aresi and arki in Sect. 3.2., a completely regular case alternation crucially depending on the DP vs. PP realization of the obligatory lower argument (see the discussion of (29) and (30)). Second, the hypothesis that vAPPL can only combine with a VP that contains a DP cannot be extended to the applicative head introducing the conceptually close to possessors source arguments discussed in Sect. 3.2. Source constructions allow for a single source object bearing accusative case while at the same time providing independent evidence from adjectival passives and nominalizations for vAPPL. We also mentioned in the previous section that comparable evidence from adjectival passives and nominalizations is available for touch-verbs like "kiss," "touch," "stroke" as well as for verbs like "bite," which show the alternation in (45) suggesting that vAPPL always introduces animate affected objects with these verbs, even when these objects surface as single objects in (45c). It is therefore implausible to account for the obligatoriness of a DP in (45b) in terms of the hypothesis that the vAPPL head introducing affectees with these verbs must combine with a VP that contains a DP. ${ }^{32}$ The dependent case alternative has no problem to deal with the relevant paradigm.

\subsection{Theme-incorporation alternations}

A further environment showing an alternation in the case of the goal depending on the realization of the lower theme argument involves theme-incorporating predicates with the verb 'give', more precisely with the bound verbal root dot-o, an allomorph of the free root din-o 'give', in examples like mistho-doto 'pay a salary to', trofo-doto 'cater for', ilektro-doto 'give electricity to'. These predicates display an alternation in SMG whereby in one variant, they involve an incorporated theme argument, mistho 'salary', trofi 'food', and ilektr- 'electricity', respectively, in addition to an independent goal, while they can also appear with the theme projected as a separate argument, in a regular goal ditransitive construction with 'give.' The relevant alternation is exemplified in (57) and (58) with the a. examples exhibiting the distransitive structure, vs. the b. examples the incorporated structure. ${ }^{33}$

ent genitive in (45b), the accusative affected possessor in (45c) cannot be introduced by vAPPL but must be assumed to be merged in a different position.

${ }^{32}$ Of course, it is always possible to assume that there are two vAPPL heads combining with these verbs, cf. Baker and Bobaljik (2017: fn. 10) for relevant discussion, but we do not find such an analysis explanatory.

${ }^{33}$ An anonymous reviewer points out that not all constructions with -doto have transparent semantics and not all of them can be analyzed in terms of theme incorporation. Relevant examples include epi- 

a. Din-o tu stratioti mistho
give-1SG the soldier.GEN salary.ACC
'I give the soldier a salary.'
b. Mistho-dot-o ton stratiot-i
salary.give-1SG the soldier.ACC
'I pay the soldier.'
a. Din-o tu ftoch-u trofi
give-1SG the poor.GEN food.ACC
'I give the poor food.'
b. Trofo-dot-o ton ftocho
food.give-1SG the poor.ACC
'I cater the poor.'

What we observe is a stark contrast in the morphological realization of the IO depending on the projection of the theme as a separate argument or not. So, in the (a) examples where there are two arguments inside the vAPPL domain, the IO is realized with genitive, while theme incorporation yields realization of the IO as accusative, seen in the (b) examples above. This is one additional piece of evidence that the SMG genitive is tied to the presence of a lower DP in the vP domain.

Importantly, alternating incorporated predicates of this kind are found in the diachrony of Greek and can therefore form the basis of a diachronic prediction: if our analysis is on the right track, and CG genitives and datives are indeed lexical cases linked to specific theta roles and not to the presence of another argument in a relevant domain, then we predict that CG datives/genitives should retain their case in alternations like the ones above involving theme-incorporation. Strikingly, this prediction is indeed borne out as we can see in (59) below, with data from Isocrates and Xenophon, both writing between the 5th and the 4th century BC:
a. Misth-on did-ontes tois naut-ais
payment-ACC give-PTCP the crew-DAT.PL
'we paid the crew out'
(Isocrates, In Callimachum, 60, 7)
b. ekei de Kunisko-s hum-in misthodot-ēsei
there then Kyniskos-NOM us-DAT hire-FUT.3SG
'there Cyniscus will take you into his service'

(Xenophon, Anabasis 7, 1:13)

Example (59a) is again the ditransitive construction with the DO and the IO projected independently, while (59b) involves the incorporated theme. The striking difference between the CG case and the SMG facts discussed above is that in CG the goal IO is

doto 'provide additional financial support', where the prefix epi- expresses the 'additional' component, and plio/mio-doto 'offer a bigger/smaller price in an auction', where 'plio/mio' mean bigger and smaller, respectively. Both of these constructions have a comparative component, and the theme is understood as expressing an amount of money. We do not have a full analysis to offer to these cases, but we would like to point out that since we are working in a framework that takes word formation to always take place in syntax, we would still want to derive the relevant constructions syntactically. We think that it is possible to analyze these prefixes as moving from a theme position, perhaps leaving a null theme behind (interpreted as 'money' in both constructions). 
realized as dative in both constructions, unlike in SMG where the goal IO is realized either as genitive or as accusative conditioned by the existence of an independent argument inside the vP.

\subsection{The distribution of high applicatives: Unaccusatives vs. unergatives}

The dependent case analysis of SMG genitives generates new predictions concerning their distribution in high applicative constructions. Specifically, high applicatives are expected to canonically surface bearing dependent genitive in unaccusatives but not in unergatives in SMG, a prediction that is borne out, as will be seen in this section. We first introduce some background on high applicatives and then proceed to the relevant facts. ${ }^{34}$

Building on Marantz (1993) and Pesetsky (1995), Pylkkänen (2002/2008) argues that there are two types of applicatives cross-linguistically, what she calls "High Applicatives" and what she calls "Low Applicatives." Low applicatives relate a recipient or a source to an individual which is the internal argument of a verb, while high applicatives relate an individual to an event. As a result of their semantic definition (Pylkkänen 2002:23), only high applicative heads can combine with unergatives. Since low applicatives involve a relation between the DO and IO, IOs cannot appear in a structure that lacks a DO (transitivity restriction). Moreover, since low applicatives imply transfer of possession, they make no sense with verbs that are completely static (restriction on verb semantics): for example, an event of holding a bag does not plausibly result in the bag ending up in somebody's possession. High applicatives, on the other hand, have no problem combining with VPs such as hold the bag since somebody could benefit from a bag-holding event. Pylkkänen discusses six languages and shows that in English, Japanese and Korean with low applicatives neither unergative nor stative verbs can be applicativized while in Luganda, Venda and Albanian with high applicatives they can. The examples below illustrate these two differences for English and Luganda, respectively:

$$
\begin{aligned}
& \text { a. *UNERGATIVE VERB } \\
& \text { *I ran him }
\end{aligned}
$$

\footnotetext{
${ }^{34}$ Note that we have already included high-applicatives in the previous sections, i.e. experiencers and affected possessors of the types we discussed are presumably also high applicatives. However, we did not focus on their nature as high applicatives because this was not relevant to what we had to say. There is evidence that the typology of applicative heads is richer than sometimes assumed. See Bosse et al. (2012) for a typology of applicative heads introducing unselected possessor, benefactive, attitude holder and affected experiencer arguments, and for a formal analysis of the head Affect introducing the latter. We should also clarify that, as has already become evident from the structures we proposed in Sects. 3.13.5, we are not subscribing to Pylkkänen's view that low applicatives are introduced below the root and high applicatives above it. We are rather assuming that vAPPL always attaches above the Root following Anagnostopoulou (2003) and Georgala (2012) who provide evidence for high attachment even for low applicatives in SMG. See Bruening (2010) for evidence that the same holds for English low applicatives (his arguments can be extended to SMG). We are furthermore assuming that non-selected high applicative arguments form a broader typology within and across languages, following Bosse et al. (2012). There are alternative ways of deriving the semantics and selection/transitivity restriction differences between high and low applicatives, either by adopting Georgala's (2012) thematic vs. expletive applicative analysis for high and low applicatives, respectively, or by adopting Bruening's (2010:552-553) movement to vP analysis of low applicatives.
} 
b. *STATIC VERB

*I held him the bag

a. $\checkmark$ UNERGATIVE VERB

Luganda

Mukasa ya-tambu-le-dde Katonga

Mukasa PAST-walk-APPL-PAST Katonga

'Mukasa walked for Katonga.'

b. $\quad \checkmark$ STATIC VERB

Katonga ya-kwaant-i-dde Mukasa ensawo

Katonga PAST-hold-APPL-PAST Mukasa bag

'Katonga held the pot for Mukasa.'

Pylkkänen's diagnostics, combined with the present hypothesis that genitive case assignment is subject to the dependent case rule in (24) lead to the following predictions for SMG applicatives.

\section{New predictions for $S M G$}

a. If SMG is a high applicative language (Anagnostopoulou 2003; Georgala 2012) and a dependent genitive language (as claimed here), then a high applicative IO is expected to receive genitive with a static verb but will not be able to receive genitive with an unergative verb.

b. High applicatives are expected to canonically receive genitive with unaccusatives but not with unergatives.

The reason why we expect this is because dependent genitive case has been shown to be sensitive to a lower argument in the vP domain, and hence high applicatives are expected to canonically surface with dependent genitive when a lower argument in the vP-domain is present, namely with static transitive verbs and unaccusatives. On the other hand, genitive is expected not to be possible in unergative contexts, since there is no lower argument for genitive to be assigned in opposition to. Of course, whether or not we expect genitives in high applicatives also depends on how high vApplP is merged. If vApplP is very high, i.e. outside VP, then genitive should not be assignable to the applied object according to the rule in (24). We have already seen that genitive can be assigned to high applicatives in SMG (see, for example, the discussion of experiencers and affected arguments in the preceding sections) providing evidence that the vAppl head introducing high applicatives is inside the VP, at least in the cases we have discussed so far. ${ }^{35}$

Turning now to the predictions in (62), we see that they are both borne out. As shown in (63), genitive arguments are freely licensed with static predicates of the hold the bag-type in SMG. Note that the context is manipulated in such a way that the IO is not interpreted as a possessor of the DO:

\footnotetext{
${ }^{35}$ In a broader typology of applicatives (see fn. 34), it is possible that there are applicatives generated higher than Voice, i.e. outside the VP-domain, see e.g. Bosse et al.'s (2012) analysis of affected arguments in Japanese. Greek seems to generally behave like a low attachment language, at least for the cases we have been discussing so far.
} 


Tha krati-so tis Maria-s mia stigmi tin kanata gia na

FUT hold-PFV.1SG the Maria-GEN one moment the pot-ACC for SUBJ

bore-si na vgal-i to palto tis

can-PFV.3SG SUBJ take off-3SG the coat her

'I will hold for a moment the pot for Maria, so that she can take off her coat.'

On the other hand, genitive applicatives are disallowed with most unergatives, as expected by $(62 a):^{36}$
a. *Etrek-sa/
perpati-sa/ kolimpi-sa/
xorep-sa
run-PST.1SG/ walk-PST.1SG/ swim-PST.1SG/ dance-PST.1SG
tu Petr- $u$
the Petros-GEN
'I ran/walked/swam for Petros.'
b. *Evik-sa/fterni-stika tu Petr-u
cough/sneeze-PST.1SG the Petros-GEN
'I coughed/sneezed and Petros was affected.'

While this asymmetry between static verbs and unergatives with genitive high applicatives is puzzling from Pylkkänen's perspective and has not been understood so far in the literature on applicatives, it is expected from the present perspective, lending further support to the dependent case analysis of SMG genitives.

The second prediction in (62) is also borne out. While genitive high applicatives cannot be added to unergatives, as we just saw, they are productive and can freely be added to unaccusatives, receiving an affected interpretation with different flavors (malefactive/benefactive) depending on the precise material included in the lower $\mathrm{VP}: 37$
a. Tis Maria-s tis
espa-se
to vazo
the Maria-GEN her.CL.GEN break-PST.3SG the vase.NOM
tis mitera-s tis
the mother-GEN her.GEN
'Her mother's vase broke and Maria was affected by it.'

\footnotetext{
${ }^{36}$ Georgala (2012:106) claims that unergatives do license high applicatives on the basis of examples like tragudao tu Petru 'sing Petros-Gen/I sing for Petros' and xamogelao tu Petru 'smile Petros-GEN/I smile at Petros'. She does note, however, that manner of motion verbs as in (64a) are ungrammatical, and the same holds for verbs of bodily processes (Levin 1993), as shown by (64b). In the present analysis, the well-formed examples she discusses are not high applicatives. This is supported by the observation that they only have an interpretation where the subject is smiling/singing to Petros, not for him or in place of him (e.g. because he has a sore throat and cannot perform in the case of singing). We propose that they have a lexically governed genitive of the type found with 'tilefonao' and 'milao' in (13) above, which we proposed to treat as bearing non-dependent, prepositional/inherent genitive in Sect. 3.1. We thank an anonymous reviewer for their input concerning this point. Another anonymous reviewer finds that the 'for me' reading is possible with the verb 'xorevo' and provides an example with a first person clitic. It is not entirely clear to us what kind of interpretation the reviewer has in mind, but it is possible that they have in mind an ethical dative interpretation which is usually limited to 1 st (and 2 nd, in exclamative contexts) person clitics in SMG and is subject to very different restrictions than those discussed here (see Michelioudakis and Kapogianni 2013 for discussion).

${ }^{37}$ We thank an anonymous reviewer for asking the unergative/unaccusative question, which led us to include prediction (62b) in the discussion.
} 

b. Tis Maria-s tis
epe-se to pedhi tis
the Maria-GEN her.CL.GEN fall-PST.3SG the child.NOM her.GEN
ke xtipi-se
and injure-PST.3SG
'Her child fell and got injured and Maria was affected by it.'

We may conclude that the hypothesis that genitive is dependent case subject to the rule (24) correctly accounts for the environments where genitive high applicatives are possible and impossible in SMG. The distribution of genitive high applicatives can thus be seen as a further argument in favor of genitive as dependent case.

Before closing this discussion, however, it is necessary to address a complication. ${ }^{38}$ The dependent genitive approach correctly predicts that high applicatives with unergatives will not receive genitive case, but does not predict that unergatives with high applicatives will be altogether ungrammatical. If genitive applicatives are excluded with unergatives due to the lack of a lower case competitor, the prediction is rather that such applicatives would be possible with a different case marking, namely accusative (in opposition to the higher external argument; or even nominative if they are generated above Voice). This is clearly incorrect, since the following sentences are completely ruled out on the relevant reading: ${ }^{39}$
a. *Etre-ksa/ perpati-sa/ kolimpi-sa/ xore-psa run-PST.1SG/ walk-PST.1SG/ swim-PST.1SG/ dance-PST.1SG ton Petro
the Petros-ACC
'I ran/walked/swam for Petros.'
b. *Evi-ksa/fternisti-ka ton Petro cough/sneeze-PST.1SG the Petros-ACC 'I coughed/sneezed and Petros was affected.'

Thus, the analysis of unergatives is incomplete, especially in view of the fact that low applicatives canonically receiving genitive may surface with accusative in the absence of a low competitor, as was seen with source arguments (data in (32) and (33)) and with goal arguments in noun-incorporation contexts discussed in the previous section. The task then becomes to define dependent case assignment to IOs in such a way, so as to allow for low applicative sources and goals to receive dependent accusative case in opposition to the external argument (EA) if a lower competitor is absent, but to prevent IOs from receiving accusative case in opposition to the EA in high applicatives combining with unergatives. We have to leave this for future research. ${ }^{40}$

\footnotetext{
${ }^{38}$ This was pointed out by two anonymous reviewers and Julie Legate (p.c.).

${ }^{39}$ Some of these examples become grammatical on a causative-like reading, i.e. 'I made Petros walk (while walking with him).'

${ }^{40}$ There is also the option to treat the ungrammaticality of applicatives with unergatives as a selection problem and not as a case problem. This is the solution proposed by Harley et al. (2016:102) for Hiaki where applicatives may combine with agentive and causative verbs but not with unaccusatives (we thank Julie Legate, p.c. for making us aware of this fact). Witness the contrast in (i):
} 


\subsection{Causatives}

There are a number of criteria for classifying datives/genitives as dependent provided in (67):

Criteria for classifying datives/genitives as dependent

a. When the goal is dative/genitive with all ditransitive verbs.

b. When the dative/genitive is used for the causee of a causative formed from a transitive verb.

c. When the language does not allow double object constructions with two accusative or absolutive objects.

d. When the goal/experiencer receives dative/genitive in dyadic unaccusatives but not in monadic unaccusative constructions.

e. When the goal argument receives dative/genitive in constructions where the lower argument is projected as a DP and accusative or nominative when the lower argument is missing, is realized as a PP or it undergoes incorporation.

f. When high applicatives can receive genitive case with static transitive verbs and unaccusatives but not with unergatives.

Criteria a-d are drawn from the discussion in Baker (2015:134-135). Criterion e has been added on the basis of case alternations with experiencers and sources (Sect. 3.2), idioms with clitics (Sect. 3.3), affected possessors/experiencers (Sects. 3.4, 3.5) and theme incorporation contexts (Sect. 3.6). Criterion $\mathrm{f}$ has been added on the basis of our discussion of high applicatives (Sect. 3.7). We have seen so far that SMG genitives satisfy criteria a, d, e and f. In this and the next section we will discuss criteria $b$ and $c$ for SMG, as they present some interesting puzzles shedding further light on the conditions of dependent genitive and accusative case assignment in SMG.

It is well-known that in many languages causative light verbs (like fare in Italian, faire in French (Kayne 1975; see e.g. Folli and Harley 2007 for discussion and references) and causative morphemes (e.g. ase/sase in Japanese; Miyagawa 2001; Pylkkänen 2002, 2008) yield monoclausal case domains with the systematic property that the embedded causee argument receives accusative case when an intransitive verb is causativized and dative case when a transitive verb is causativized; in the latter construction, the embedded object receives accusative. The following Japanese example (from Folli and Harley 2007:221, ex. (38)) illustrates this; cf. Baker and Vinokurova 2010; Baker 2015:13, ex. (18) for the same pattern in Sakha:

(i) Inepo Hose-ta ya'u-ta hiapsi-tua-ria-k
1sG Jose-ACC leader-ACC heart-CAUSE-APPL-PRF
'I fed the leader for Hose.' (lit. 'I caused the leader to have a heart.')
b. *Un tasa Maria-ta hamti-ria-k
the cup Maria-ACC break.INTR-APPL-PRF
'The cup broke for/on Maria.'

Assuming that applicatives in Hiaki always combine with vPs (because they can follow a causative morpheme, as shown in (ia)), Harley et al. propose that they can only select agentive/causative $v$ heads such as $v_{\text {Cause }}$ and $v_{\text {Do }}$ and not the head $v_{\text {Happen }}$ present in unaccusatives (see Folli and Harley 2004 for "flavors' of v). Extending this reasoning to SMG, one could say that high applicatives in this language are not allowed to combine with $v_{\text {Do }}$. 


\section{Intransitive embedded clause}

a. Calvin-ga Hobbes-o ik-ase-ta

Calvin-Nom Hobbes-ACC go-CAUS-PAST

'Calvin made Hobbes go.'

\section{Transitive embedded clause}

b. Calvin-ga Hobbes-ni pizza-o tabe-sase-ta

Calvin-Nom Hobbes-DAT pizza-ACC eat-CAUS-PAST

'Calvin made Hobbes eat pizza.'

As argued for in Harley (1995), Folli and Harley (2007), Baker and Vinokurova (2010) and Baker (2015), this is a straightforward argument for dependent/configurational case because the assignment of dative vs. accusative on the causee argument depends on whether a lower object is present or not.

Greek does not have a productive pattern of monoclausal causatives of the type seen in (68), and, therefore, this criterion does not straightforwardly apply in this language. ${ }^{41}$ However, there are traces of this pattern in examples that can be analyzed as causative. For example, example (69b) plausibly involves causativization of the intransitive (69a), and the causee is assigned accusative. On the other hand, (70b) can be seen as a causative of a transitive, yielding a ditransitive causative with genitive on the causee and accusative on the embedded object (cf. Pylkkänen 2008:123, ex. (104) who analyzes the alternation between kiru 'put on one's body/wear' and kiseru 'put on someone else's body' in Japanese as causativization).
a. H Maria kima-t-e the Maria-Nom sleep-NACT-3SG
'Maria sleeps.'

b. O Kosta-s kimi-se tin Maria the Kostas-Nom sleep-ACT.Pst.3Sg the Maria-ACC 'Kostas made Maria sleep.'
a. H Maria fore-se tin fusta tis the Maria-Nom put on-ACT.PST.3SG the skirt-ACC hers-GEN 'Maria put her skirt on.'
b. I mama fore-se tis Marias
the mother-Nom put on-ACT.PST.3SG the Maria-GEN
tin fusta tis
the skirt-ACC hers-GEN
'Mother put on Maria's body her skirt.'

There is a set of cases which present an interesting complication. The verbs matheno 'learn' and archizo 'start', ksekinao 'start' and sinexizo 'continue' appear to allow an

\footnotetext{
${ }^{41}$ Presumably due to the fact that Greek lacks infinitives, Greek has productive biclausal causatives of the type found in English with 'make,' 'have,' 'let.' These are formed with the verbs 'kano' (make) and 'vazo' (put), the difference being that the latter verb imposes an obligation on the causee, unlike the former. As a result, the causee must be an agent with 'vazo,' while it is not subject to an agentivity restriction with 'kano' (see Folli and Harley 2007 for a comparable semantic difference shown by faire-infinitif vs. faire-par causatives in Romance).
} 
alternation in the case of the transitive causee argument, which has either genitive or accusative in the presence of a lower object, in apparent violation of the rules of dependent genitive and accusative case assignment seen so far: ${ }^{42}$
emath-e
dhisko/dhiskovolia
the Maria-Nom learn-PST.3SG discus-ACC
'Maria learned discus.'
b. O proponiti-s emath-e tis Maria-s/tin Maria
the trainer-Nom learn-PST.3SG the Maria-GEN/the Maria-ACC
dhisko/dhiskovolia
discus-ACC
'The trainer taught Maria discus.'
a. I Maria
arxi-se
Aglika
the Maria-Nom start-PFV.3SG English-ACC
'Maria started (to learn) English.'
b. Tha tis/tin arxi-so tis Maria-s/tin Maria Aglika
FUT her.CL.GEN/ACC start-PfV.1SG the Maria-GEN/-ACC English 'I will make Maria start (to learn) English'

On closer inspection, the optionality in (71b) and (72b) is only apparent. When the direct object is definite, as in examples (73), only the genitive causee is licit; the accusative one is ungrammatical:
a. Pjos ${ }^{\mathrm{ok}_{\mathrm{tis}} / * \text { tin }}$
emath-e
$\mathrm{ok}_{\text {tis }}$ Maria-s/*tin Maria
who her.CL. ${ }^{\text {ok }}$ GEN/*ACC learn-PST.3SG the Maria- ${ }^{o k}$ GEN/-*ACC
ta Aglika?
the English-?
'Who taught Maria the English language?'
b. Tha ${ }^{\mathrm{ok}}$ tis/*tin
arxi-so
${ }^{\mathrm{ok}}$ tis Maria-s/*tin Maria
FUT her.CL. ${ }^{\text {ok }}$ GEN/*ACC start-PFV.1SG the Maria- ${ }^{\mathrm{ok}}$ GEN/-*ACC
ta Aglika
the English
'I will make Maria start (to learn) English.'

The Gen vs. Acc case of the causee argument thus falls under the normal dependent case pattern when the lower argument is a DP.

A further pattern reinforces the conclusion that the genitive vs. accusative case of the higher object of these verbs is sensitive to the properties of the lower one. In examples (74) and (75) with a causative-like use of 'matheno' and 'arxizo' we see that when the lower object is a PP the higher object must have accusative case, while when it is a DP the higher object must have genitive case, a pattern that has been seen to pervasively hold in SMG:

\footnotetext{
${ }^{42}$ Note that these constructions do not passivize, similarly to faire-causatives in French (Burzio 1986) and, arguably, also fare-infinitival (FI) constructions in Italian (Folli and Harley 2007).
} 

a. $\quad$ Pjos ${ }^{\text {ok }}$ tis/*tin
emath-e
$\mathrm{ok}_{\text {tis Maria-s/*tin Maria }}$
who her.CL. ${ }^{\text {ok }}$ GEN/*ACC learn-PST.3SG the Maria- ${ }^{\circ \mathrm{ok}}$ GEN/-*ACC
ta narkotika?
the drugs-ACC?
'Who got Maria addicted to drugs?'
b. Pjos $* \mathrm{t}_{\mathrm{tis}} /{ }^{\mathrm{ok}}$ tin emath-e $*{ }_{\mathrm{tin}}$ Maria-s $/{ }^{\mathrm{ok}} \mathrm{tin}$ Maria
who her.CL. $* \mathbf{G E N} /{ }^{\circ k}$ ACC learn-PST.3SG the Maria-* GEN/- ${ }^{\circ}$ ACC
s-ta narkotika?
to-the drugs-ACC?
'Who got Maria addicted to drugs?'
a. Pjos ${ }^{\text {ok }}$ tis/*tin
arxi-se
$\mathrm{ok}_{\text {tis }}$ Maria-s/*tin Maria
who her.CL. ${ }^{\text {ok }}$ GEN/*ACC start-PFV.3SG the Maria- ${ }^{\text {ok }}$ GEN/-*ACC
tis erotisi-s?
the questions-ACC?
'Who started (asking) Maria many questions?'

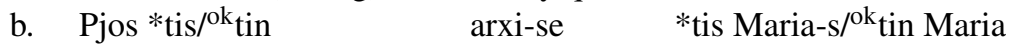
who *her.CL.*GEN/ ${ }^{\text {ok }}$ ACC start-PFV.3SG the Maria-*GEN/-ACC
s-tis erotisi-s?
to-the questions-ACC?
'Who started (asking) Maria many questions?'

On the basis of the examples in (73)-(75), we can thus conclude that the constructions formed with the verbs matheno 'learn' and arxizo 'start' are, in fact, subject to the canonical dependent case rules of SMG. What about the causatives in (71) and (72) which display optionality in case marking? To account for this pattern we propose to capitalize on the fact that in these constructions the lower object is a bare NP. Specifically, in these constructions, the lower object only optionally counts as a case competitor for the assignment of dependent genitive when it has the categorical status of an NP, perhaps because it may optionally undergo pseudo-incorporation with learn-type verbs. Notice that we cannot draw the conclusion that all NP objects are optionally ignored for dependent genitive assignment in SMG because genitive/accusative optionality is crucially limited to these particular constructions, i.e. causatives formed with learn-type verbs. ${ }^{43}$ Genitive is assigned when the lower NP counts as a case competitor and accusative is assigned when it doesn't.

\footnotetext{
${ }^{43}$ See also the discussion of verbs of ingestion giving rise to double accusative constructions in the next section. Indefinite lower arguments require further investigation. They seem to also trigger optionality in the case marking of the higher object, though accusative case on the higher object seems worse when the lower one is an indefinite than when it is a bare NP. If it turns out that ACC $>$ INDEF constructions are systematically and robustly well-formed, then lower objects must be said to optionally qualify as case competitors in the relevant constructions when they are smaller than DPs, instead of saying that they must be NPs.
} 


\subsection{Teach verbs}

SMG permits double object constructions with two accusative objects with the verbs 'teach' (didasko), 'serve' (serviro), 'pay' (plirono) (Anagnostopoulou 2001, 2003), in apparent violation of Baker's (2015) criterion c in (67):
a. teach
Dida-ksa tin Maria grammatiki
teach-PST.1SG the Maria.ACC grammar.ACC
'I taught Maria grammar.'
pay
b. Pliro-sa ton Petro ena poso
pay-PST.1SG the Petros.ACC an amount.ACC
'I paid Petros an amount.'
serve
c. Servir-a tin Maria kafe
serve-PST.1SG the Maria.ACC coffee.ACC
'I served Maria coffee.'

The reason why Baker (2015) employs this criterion is because a dependent case approach towards datives predicts the distribution of dative in ditransitives to be completely general. If there is variation in the cases goals can receive, then this potentially constitutes evidence that these cases are lexically determined by particular verbs. The question that arises, therefore, is whether the well-formedness of examples like (76) undermines the dependent case analysis of SMG genitives argued for in the preceding sections.

We argue that the answer to this question is negative. Just as with the causatives based on 'learn' and 'start' in the previous section, a closer investigation of teachverbs will lead us to conclude that the data in (76) do not actually challenge the proposal that genitive case is dependent in SMG.

We will start the discussion with the observation that the very same verbs 'teach,' 'pay,' 'serve,' may also surface with a genitive IO, as shown in (77), and the theme is obligatorily present, as predicted by the hypothesis that the IO in these examples is assigned genitive in opposition to the lower DO.

\section{Genitive construction: the theme is obligatory}

\footnotetext{
a. teach

Dida-ksa tis Maria-s * (grammatiki)

teach-PST.1SG the Maria-GEN grammar.ACC 'I taught Maria grammar.' pay

b. Pliro-sa tu Petr-u *(ena poso) pay-PST.1SG the Petros-GEN an amount.ACC 'I paid Petros an amount.' serve

c. Servir-a tis Maria-s *?(kafe) serve-PST.1SG the Maria-GEN coffee.ACC 'I served Maria coffee.'
} 
We will be calling the Acc-Acc frame in (76) 'double accusative construction' and the Gen-Acc frame in (77) 'genitive construction.'

There are two pieces of evidence showing that the IO receives regular 'downward' dependent accusative in the double accusative construction. First, in contrast to genitive IOs in constructions like (77), accusative IOs in the double accusative construction can surface as the sole complements of the verbs, i.e. the theme is optional, as shown in (78):

\section{Accusative construction: The theme is optional}
a. Dida-ksa tin Maria (grammatiki)
teach-PST.1SG the Maria.ACC grammar.ACC 'I taught Maria (grammar).'
b. Servir-a tin Maria (ena-n kafe) serve-PST.1SG the Maria.ACC a.ACC coffee.ACC 'I served Maria (a coffee).'

This shows that the goal in (78) is not assigned case in opposition to the lower theme argument. Second, the goal surfaces with nominative in passives, unlike goals in regular genitive constructions which are not allowed to alternate with nominative (see example (12)): the Maria.NOM teach-NACT.PST.3SG grammar.ACC by me 'Maria was taught grammar by me.'
a. IMaria dida-xtike (grammatiki) apo mena
b. I Maria serviri-stike (enan kafe)
the Maria.NOM serve-NACT.PST.3SG a.ACC coffee.ACC
apo ton servitoro
by the waiter
'Maria was served a coffee by the waiter.'

This provides evidence that the IO has dependent accusative assigned in opposition to the higher EA, in accordance with rule (80):

\section{Dependent accusative case rule in SMG:}

(80) If DP1 c-commands DP2 in TP, then assign U (accusative) to DP2

When the EA is not present, as in (79), then the IO cannot receive dependent accusative, and receives the next case lower in the hierarchy in (21), namely environment-sensitive nominative.

We thus conclude that 'teach,' 'pay' and 'serve' have the ability to either occur in the regular ditransitive frame with IOs bearing dependent genitive in opposition to the lower DO, in accordance with Baker's rule (24), or in an exceptional for SMG frame with dependent accusative assigned to the IO in opposition to the higher EA, in accordance with rule (80).

A key towards understanding the exceptionality of the double accusative frame in SMG is provided by the behavior of teach-verbs in adjectival passives and nomi- 
nalizations. Crucially, the Greek verbs didasko 'teach', plirono 'pay', serviro 'serve' permit both theme and goal externalization in adjectival passives (81), unlike givetype verbs which only allow theme-externalization (82). ${ }^{44}$
a. O prosfata servirismenos kafes/o prosfata servirismenos pelatis The recently served coffee/the recently served customer
b. O aplirotos logarisamos/o aplirotos ipalilos The unpaid bill/the unpaid employee
a. Ena prosfata xarismeno vivlio/*ena prosfata xarismeno pedhi A recently given book/*a recently given child
b. Ena prosfata stalmeno gramma/*enas prosfata stalmenos paraliptis A recently sent letter/*a recently sent addressee

Moreover, nominalizations in which the goal surfaces as the non-prepositional complement of the noun are impossible with the verbs forming the genitive construction (83) while they are licit with the verbs forming the double accusative construction (84):

a. To xarisma enos vivliu/*to xarisma enos pedhiou The gift of a book/*the gift of a child (i.e. to a child)

b. I anathesi mias ergasias/*i anathesi enos fititi

The assignment of a term paper/*the assignment of a student (i.e. to a student)

a. I didiaskalia ton mathimatikon/i didaskalia ton pedhion The teaching of math/the teaching of the children (i.e. to the children)

b. I taktiki pliromi ton logarisamon/i taktiki pliromi ton ipallilon The regular payment of the bills/the regular payment of the employees (i.e. to the employees)

We have already proposed in the preceding sections to interpret the prohibition against goal externalization in adjectival passives and non-prepositional goal realization in nominalizations as resulting from a condition which prevents applicative heads (vAPPL) from occurring in adjectival passives and nominalizations. Since genitive goals reside in the specifier position of VAPPL as in (27) they are not licensed. On the other hand, accusative goals of teach-verbs reside in the Root domain, as in (85), and are thus licit in (81) and (84).

\footnotetext{
${ }^{44}$ Note that the same contrast obtains in English with exactly the same verbs, as shown by the English translations of the relevant examples. Levin and Rappaport (1986) discuss this contrast in English and argue that this distribution derives from the 'sole complement generalization' according to which only arguments that may surface as the sole complements of the verbs are allowed to externalize in adjectival passives. Examples (78) show that the three SMG verbs also fall under the sole complement generalization, something that we interpreted as a by-product of the rules of dependent case assignment in SMG. At present, we remain agnostic as to whether the same type of approach can be extended to English.
} 


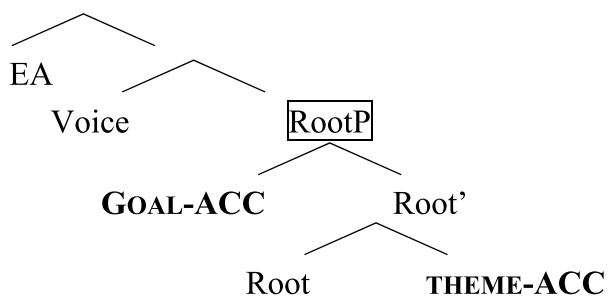

The relevant SMG verbs can be seen as causative ${ }^{45}$ versions of transitive "verbs of ingesting' (Levin 1993:213-217), broadly construed as 'taking something into the body or mind (literally or figuratively)' (Masica 1976:46). ${ }^{46}$ We saw in the preceding section that 'learn' and 'start (to learn)' give rise to causatives showing apparent optionality in the case of the IO, which, on closer inspection, depends on the properties of the DO, i.e. whether it is a DP or an NP or a PP. A similar sensitivity of the case of the higher object to the properties of the lower one can be observed for 'teach,' 'serve' and 'pay.'

First, these verbs allow for the goal to receive either accusative or genitive case when the theme is bare or indefinite, as shown in (76) and (77), but when the theme is a regular definite DP, the goal must be genitive and cannot be accusative:
a. Dida-ksa ok tis Maria-s/*tin Maria tin grammatiki teach-PST.1SG the Maria- ${ }^{\mathrm{ok}} \mathbf{G E N} / \mathbf{-}^{*} \mathbf{A C C}$ the grammar-ACC 'I taught Maria the grammar.'
b. Servir-a ${ }^{k}$ tis Maria-s/*tin Maria ton kafe serve-PST.1SG the Maria- ${ }^{\mathrm{ok}}$ GEN/-*ACC the coffee-ACC 'I served Maria the coffee.'

Second, the assignment of genitive vs. accusative case to the higher object depends on the DP vs. PP status of the lower one with the verb 'pay':

\footnotetext{
${ }^{45}$ Note that teach-verbs discussed in this section are similar but not identical to the causatives discussed in the preceding section. First, the causatives discussed in the previous section do not passivize (see fn. 42), while teach verbs do. Second, teach-verbs do not generally allow for the theme to surface as a PP (with the exception of 'pay'). Finally, they allow for the goal to receive accusative case when the definite theme is heavy; see below.

${ }^{46}$ Ingestive verbs are known in the literature to display exceptional behavior across languages, a fact which has been related to the observation that the person that consumes e.g. food, liquids (as in eat or drink) or knowledge (as in learn, study) not only controls but is also affected by the consumption event. Verbs of ingesting are therefore said to involve 'affected-agents' participating in phenomena that either typically occur with theme objects or characterize intransitive verbs. For example in Hindi (and in Greek) they can form agent-oriented active resultative participles normally formed only with themes ('the eaten boy' meaning 'the boy who ate completely'; Haspelmath 1994; cf. drunk, learned in English) and in Hindi, Berber, Amharic, Malayalam, Tariana and other languages these verbs pattern with intransitives rather than with transitives with respect to causativization (Masica 1976; Amberber 2009; see the various contributions to Newman 2009, and Næss 2011 for an overview of the relevant phenomena in different languages). It is interesting to note that 'teach' is a verb that assigns accusative to the IO in many languages where the normal case of IOs is dative (e.g. cf. the German verb 'lehren'). Note that the Greek verbs taizo 'feed', potizo 'give water to' and kernao 'offer a treat' only allow the double accusative pattern. An anonymous $N L L T$ reviewer finds that the verb kernao 'offer a treat' behaves differently than 'teach,' 'pay' and 'serve' with repect to nominalizations, adjectival passives and passives. We are not systematically discussing 'feed,' 'give water to' and 'offer a treat' here.
} 

a. Pliro-sa ${ }^{o k}$ tis Maria-s/*tin Maria tis dosi-s pay-PST.1SG the Maria- ${ }^{\mathrm{ok}} \mathbf{G E N} /-* \mathbf{A C C}$ the installments-ACC 'I paid Maria the installments.'
b. Pliro-sa *tis Maria-s/ok tin Maria pay-PST.1SG the Maria-*GEN/- ${ }^{\circ}$ ACC se dosi-s/se idho-s to instalments-ACC/in kind-ACC 'I paid Maria in installment/in objects (i.e. I bartered).'

Finally, the higher object can be accusative when the lower definite object is made heavy, as shown in (88), i.e. the Gen/Acc optionality of the goal resurfaces in the presence of a heavy theme.
a. Dida-ksa ${ }^{\mathrm{ok}}$ tis Maria-s/ $/{ }^{\mathrm{k}}$ tin Maria teach-PST.1SG the Maria- ${ }^{\mathrm{ok}} \mathbf{G E N} /{ }^{\mathrm{ok}} \mathbf{A C C}$
tin grammatiki ton Arxai-on Ellinik-on the grammar-ACC the Ancient Greek-GEN 'I taught Maria the grammar of Ancient Greek.'
b. Pliro-sa ${ }^{\mathrm{ok}}$ tis Maria-s/ $/{ }^{\circ}$ tin Maria ta xrimata pu tis pay-PST.1SG the Maria- ${ }^{\mathrm{ok}}$ GEN/- ${ }^{\mathrm{ok}}$ ACC the money-ACC that CL-GEN ofila owe-PST.1SG
'I paid Maria the money I owed her.'

Taken together, the above presented facts present evidence that the case realization of the higher object depends on the properties of the lower object with teach-verbs, as expected by a configurational approach to genitive as dependent case upwards. As far as sensitivity to definiteness is concerned, we can treat 'teach-verbs' similarly to the way we have treated causative 'learn' and 'start (to learn)' in the preceding section. The grammaticality of genitive and the ungrammaticality of accusative on the higher object in (86) can be accounted for if a definite DP obligatorily triggers dependent genitive assignment to the higher argument due to rule (24). On the other hand, the lower object only optionally counts as a case competitor for dependent case assignment when it is indefinite or a bare NP, perhaps because it may optionally undergo pseudo-incorporation into 'teach' and verbs of ingestion, similarly to what has been suggested in Sect. 3.8 for 'learn' and 'start (to learn).' The fact that a lower DP triggers genitive and a lower PP triggers accusative in the examples in (87) featuring 'pay' shows that PPs are ignored for the calculation of dependent genitive assignment. Finally, the fact that the higher object either receives genitive or accusative when the lower one is heavy, as in (88), can receive an explanation under the hypothesis that heavy themes optionally undergo rightward movement to a position outside the VP domain, and thus they no longer qualify as case competitors for dependent genitive assignment. ${ }^{47}$

\footnotetext{
${ }^{47}$ We would like to thank an anonymous $N L L T$ reviewer for suggesting the extraposition analysis for heavy themes.
} 


\subsection{Interim summary}

We have argued in the preceding sections that CG dative and genitive meet the criteria for idiosyncratic cases (in monotransitives) and inherent cases (in ditransitives), thus qualifying as lexically governed cases in terms of Marantz's case hierarchy (21). On the other hand, there is ample evidence that the SMG genitive qualifies as dependent case which is assigned in opposition to a lower argument in the VP domain, in accordance with Baker's (2015) definition of dependent dative. The SMG genitive is productive and general in ditransitives but very rare in monotransitives, it never occurs with affected and experiencer arguments of monadic sensation and psych

verbs, and it systematically occurs on the higher argument of dyadic unaccusative verbs. Genitive alternates with nominative and accusative when the lower theme argument is either missing (e.g. with sources, alternating idioms with clitics, affected possessors/experiencers of monadic verbs) or is realized as a PP (e.g. Gen-Nom alternations with 'please' and 'is sufficient,' Gen-Acc and Gen-Nom alternations with affected possessors). Genitive alternates with Accusative in constructions displaying theme-incorporation into 'give,' in striking contrast to CG where theme incorporation did not affect the dative case of the goal. Finally, dependent genitive can also explain why high applicatives are allowed to receive genitive case with static transitive verbs and unaccusatives, but not with unergatives. In the last part of Sect. 3, we discussed causatives formed with 'learn' and 'start' and ditransitives formed with 'teach,' 'serve' and 'pay' which appear to show an optionality in the case of the higher object as either genitive or accusative. We argued that this optionality is only apparent; a more detailed investigation of the relevant constructions reveals that genitive vs. accusative case on the higher object depends on properties of the lower one: definiteness, heaviness, PP- vs. DP-status. This is expected if genitive is subject to rule (24) and is assigned in opposition to a lower argument of the appropriate type.

\section{Dependent genitive and accusative case in Greek ditransitives: Spelling out the details}

It is time to become more precise on how exactly dependent genitive and dependent accusative case are assigned in SMG. In this section, we will argue that all we need to derive the facts we have seen are three rules, namely the dependent dative rule (24), repeated here, the dependent accusative rule (80), repeated here, and the condition on case marking (89) which prevents an argument that has already valued its case from being a case competitor for dependent case assignment (cf. Baker 2015:48-49, def. (36a) for accusative, (36b) for ergative; in (89) we are replacing ergative with dative).

\section{Dependent dative case rule in $S M G$}

If XP c-commands ZP in VP, then assign $\mathrm{U}$ (dative) to $\mathrm{XP}$

Dependent accusative case rule in SMG:

If DP1 c-commands DP2 in TP, then assign U (accusative) to DP2 


\section{Condition on case marking}

a. If there are two distinct NPs in the same domain such that NP1 ccommands NP2, then value the case feature of NP2 as accusative unless NP1 has already been marked for case.

b. If there are two distinct NPs in the same domain such that NP1 ccommands NP2, then value the case feature of NP1 as dative unless NP2 has already been marked for case.

Mark Baker (p.c.) points out that (89) needs to be parametrized. As argued for in Baker (2015), it doesn't hold in tripartite languages like Nez Perce where ergative and accusative are assigned simultaneously. Moreover, (89) probably doesn't hold in Tamil which has experiencer verbs with Dat subjects and Acc objects. On the other hand, Dat>Acc constructions are absolutely impossible in Greek for which the case marking condition (89) and the way in which it interacts with the domains of application of the dative and the accusative rule, VP vs. TP, is crucial.

Based on a comparison of SMG, NG and English, we will also develop a partial typology depending on whether a language has a dependent dative rule applying in the vP domain or not. We will finally discuss passives in $\mathrm{MG}$, as opposed to CG.

\subsection{How is dependent case assigned to IOs and DOs in SMG?}

Consider tree (90) for SMG active ditransitives. Following Alexiadou et al. (2006, 2015) we are decomposing the upper $v P$ domain into the verbalizing head $v$ with introduces eventiveness and, when combined with a resultative RootP, causation, and a Voice head introducing the external argument (EA). 'VP' in rule (24) could be vP in (90), i.e. the complement of Voice, as proposed by Baker (2015), ${ }^{48}$ or, alternatively, 'VP' can also be equated with VoiceP in (90), i.e. with the highest projection of the VP domain. Nothing crucial hinges on this for what we have to say.

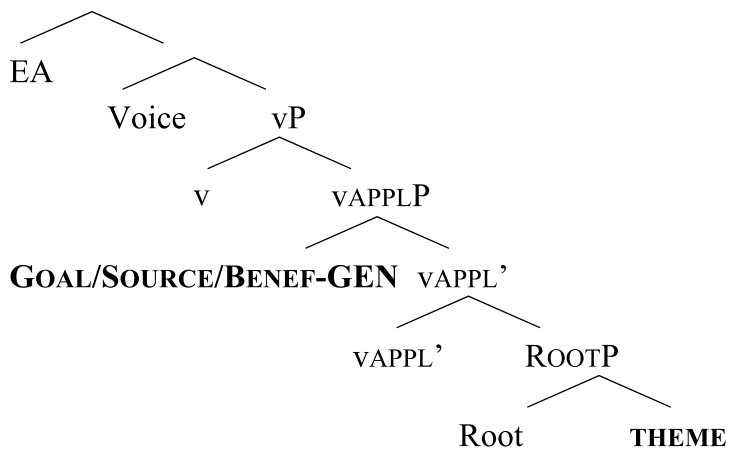

Since the domain of application for the dative rule is the vP, the first thing that happens in (90) is the application of the dative rule (24). As a result, the IO is assigned

\footnotetext{
${ }^{48}$ On this view, the relevant domain for dative case assignment is always the complement of Voice regardless of its label. If there are constructions in which Voice selects for vAPPLP and eventive $\mathrm{v}$ is lower down, then the dative domain is vAPPLP.
} 
genitive case in opposition to the lower theme argument which has not yet been marked for case (since the domain of application for the accusative rule is TP, see below). Importantly, dependent genitive case assignment is not affected by the transitivity of Voice, i.e. it is irrelevant to the application of (24) whether Voice has a specifier, as in the active (90), or not, as in the passive (91). All that matters for rule (24) to apply is that the vP includes a caseless DO c-commanded by the IO, and this holds in both (90) and (91).

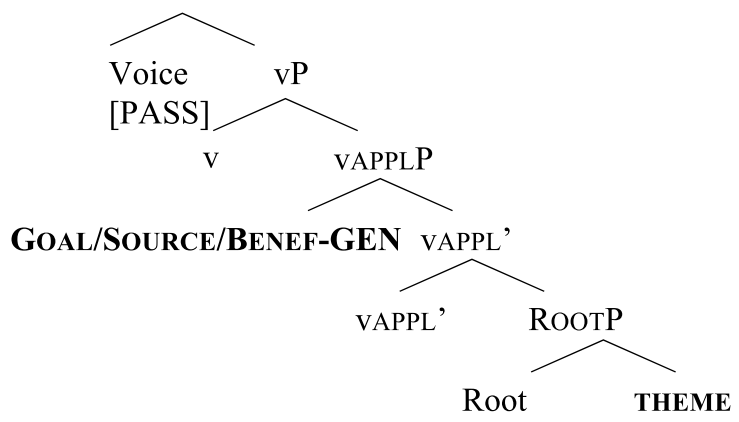

This explains why dependent genitive on the IO must be retained in SMG passives, as was seen by the ungrammaticality of (12), repeated here: ${ }^{49}$
a. *O Petr-os
do-thike
ena pagoto
the Petros.Nom give-NACT.PST.3SG an ice cream.ACC
'Petros was given an ice cream.'

On the other hand, the case of the theme DO is sensitive to the transitivity of Voice. The theme is assigned accusative when the EA is present, as in (90), and is assigned nominative when the EA is absent, as in (91) which contains passive Voice. Well-formed examples like (92) show that SMG allows Acc-Nom alternations in ditransitives. ${ }^{50}$

H epistoli tu do-thike tu Petr-u
the letter.NOM him.CL-GEN give-NACT.PST.3SG the Petros-GEN
apo tin Maria
by the Maria
'The letter was given to Petros by Maria.'

The Acc-Nom alternation affecting themes in ditransitives can be straightforwardly explained if the accusative rule follows the application of the dative rule, and here the case marking condition (89) and its interaction with the domains of application of the dative vs. accusative rule is crucial. In active (90), rule (80) applies at TP assigning accusative to any DP that is c-commanded and has not been assigned case. As a

\footnotetext{
${ }^{49} \mathrm{An}$ anonymous reviewer points out that the explanation for the ungrammaticality of (12) also requires that a genitive-marked goal in SMG can't raise to subject position and have its case valuation overwritten as nominative. See Sect. 4.3 for more discussion of this.

${ }^{50}$ Provided that goals undergo clitic doubling, see Anagnostopoulou (2003) for details.
} 
result, the theme is assigned dependent accusative in opposition to the EA. The higher goal/source/benefactive argument, which has been dative-marked by rule (24) at vP, is ignored for dependent accusative assignment due to (89). In passives, however, the theme cannot be assigned dependent accusative because there is no appropriate ccommanding argument for rule (80) to apply. The EA is missing and the higher dative argument has already been marked for genitive case by (24), thus being excluded as a case competitor by condition (89). As a result, the theme in (92) must surface with the next case lower-down in the hierarchy, namely environment-sensitive nominative.

We can extend this basic account to all constructions we have discussed in Sect. 3. Transitive constructions featuring a nominative, a genitive and an accusative DP, are structurally represented similarly to (90), see e.g. structure (41) for idioms with accusative clitics and structure (47) for affectee genitive possession constructions. Rule (24) applies at vP leading to assignment of dependent GEN case to the higher DP vP-internally, in opposition to the lower vP-internal DP. At TP, rule (80) applies leading to the assignment of dependent ACC case to the lowest argument, in opposition to the higher EA. The argument bearing GEN which occurs between the EA and the DO is ignored for dependent accusative assignment because it has already been marked for case and does not qualify as a case competitor. Finally, the EA receives environment-sensitive NOM. On the other hand, all GEN>NOM constructions (e.g. experiencer constructions of the piacere-type, affectee Gen-Nom constructions, unaccusatives with high applicatives) are structurally represented as in (91) with a higher experiencer, possessor, applicative DP and a lower DP argument introduced at the Root-level (theme, possessee etc.). ${ }^{51}$ Rule (24) applies at vP, and the higher argument receives GEN. At TP, rule (80) cannot apply because the EA is missing and the higher object has already been assigned GEN. As a result, the lower object receives environment-sensitive NOM.

In Sect. 3, we have seen that rule (24) is suspended under the following conditions:

(i) When the lowest DP introduced by the Root is missing: this is e.g. the case in source applicatives in (32) and (33) where the source has ACC in the absence of a theme, see structure (34); in Gen-Nom in alternations involving idioms when expletive clitics are missing, see (42); with monadic experiencer and sensation verbs where the experiencer has NOM, e.g. (51c) and (52c), see structure (53).

(ii) When the lowest argument is an obligatory or optional PP: e.g. in Gen-Nom alternations displayed with aresi 'please' and arki 'is sufficient' where the theme is an obligatory PP, see examples (29) and (30b); in Gen-Acc alternations involving possessors/affectees where the possessor is optionally realized as a PP, see examples in (45) and structure (47); in constructions featuring experiencers/possessors where the possessed argument is optionally realized as a PP, see examples (51) and (52).

(iii) When the theme undergoes incorporation, as in examples (57)-(58).

In these constructions, rule (24) is inapplicable, and the IO now receives ACC or NOM, depending on whether there is a higher EA or not. If EA is present, then the IO receives dependent ACC by rule (80). If EA is absent, then rule (80) does not apply, and the single argument receives environment-sensitive NOM.

${ }^{51}$ The relevant structures may or may not contain (expletive) Voice, depending on whether they have NonActive or Active morphology (see Alexiadou et al. 2015). If Voice is absent, then 'VP domain' in Rule (24) is vP. 
What about causatives with matheno 'learn' and arxizo 'start (to learn)' discussed in Sect. 3.8 and didasko 'teach', plirono 'pay' and serviro 'serve' discussed in Sect. 3.9 which appear to exceptionally allow for accusative causees and goals in the presence of overt lower objects, in apparent violation of rule (24)? In order to account for these cases, we have capitalized on the fact that genitive causees and goals are also licit in these constructions. Moreover, genitive on causees and goals is forced when lower objects are definite DPs, while accusative is forced when the lower object is realized as a PP. On the basis of these observations, we proposed that the dependent genitive rule (24) must apply when the lower object is a definite DP, leading to obligatory genitive case on the causee and the goal. When these arguments surface as accusative, then rule (24) does not apply because the lower object has been rendered invisible for dependent dative assignment. This happens when it is a PP, a heavy NP undergoing rightward movement outside the vP or it is a bare/indefinite NP allowed to undergo pseudo-incorporation with learn-type verbs. In this case, causees and goals receive dependent accusative case in opposition to the higher EA. Passivization with 'teach'-verbs ${ }^{52}$ discriminates between the two options. When the goal is assigned GEN it is retained in passives, and the theme receives environment-sensitive nominative in the absence of EA, as in (93a). When rule (24) does not apply, the goal receives dependent ACC in opposition to the EA in active sentences, and receives environment-sensitive NOM when the EA is absent in passives, as in (93b):

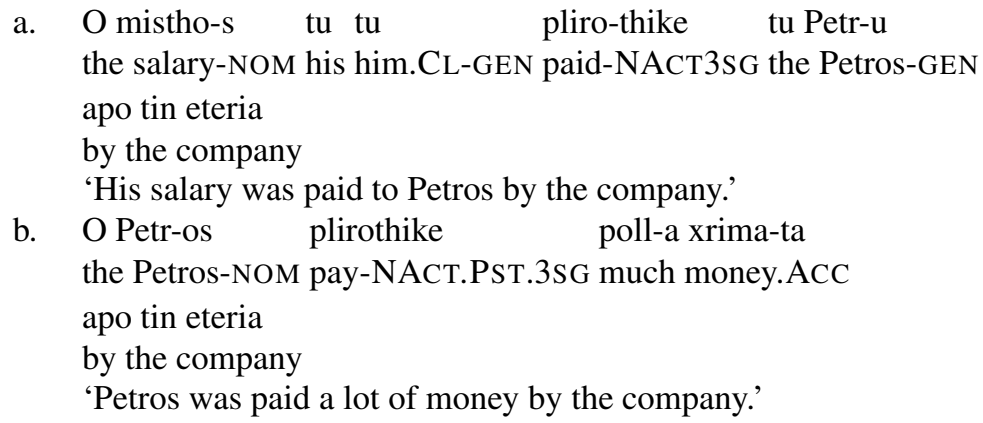

There is a final issue that needs to be addressed before closing this discussion. Baker and Vinokurova (2010) and Baker (2015) argue that the VP-domain, more precisely the complement of Voice, ${ }^{53}$ i.e. the vP in (90) and (91), is a case domain, as stated in rule (24), because it is a spell-out domain. If this is the case, then the DO is expected to move to the edge of vP in order to be visible for dependent accusative assignment. If it remains in its base position, it will be inaccessible to the EA. Baker and Vinokurova (2010) and Baker (2015) argue for a movement-to-the edge analysis for languages with Differential Object Marking (DOM; Bossong 1985, 1991; Aissen 2003) like Sakha. In Sakha, like many other DOM languages, accusative case marking is sensitive to specificity/definiteness and does not occur with indefinites. Crucially, the theme can either be unmarked or accusative, and its position varies

\footnotetext{
${ }^{52}$ Recall that causative 'learn' and 'start (to learn)' do not passivize, see fn. 42.

${ }^{53}$ Our Voice is v in Baker and Vinokurova (2010) and Baker (2015). Our vP is vAPPLP in them.
} 
with respect to the dative goal. When the theme is unmarked for case, it must be a non-specific indefinite and must follow the goal, as shown in (94a). On the other hand, when the theme is marked for accusative case, it is specific or definite and must precede the goal, as shown in (94b):

SAKHA (Baker and Vinokurova 2010:13, ex. (11)

a. Min Masha-qa kingie-(\#ni) bier-di-m

I Masha-DAT book-ACC give-PAST-1SS

'I gave Masha books/a book.'

b. Min kingie-*(ni) Masha-qa bier-di-m

I book-ACC Masha-DAT give-PAST-1SS

'I gave the book to Masha.'

The same variation in word order has been observed by Bhatt and Anagnostopoulou (1996) for Hindi.

However, the situation in SMG, a non-DOM language, ${ }^{54}$ is very different. SMG DOs bear obligatory overt accusative case morphology, regardless of their position and interpretation, and there is no evidence that DOs obligatorily move to the edge of vAPPLP or vP. While SMG ditransitives allow for both $\mathrm{IO}>\mathrm{DO}$ and $\mathrm{DO}>\mathrm{IO}$ orders, as shown in (95), the $\mathrm{DO}>\mathrm{IO}$ order is never obligatory and does not seem to be associated with interpretational effects.
a. Edho-sa
tu Petr-u
tin tsanda
give-ACT.PST.1SG the Petros-GEN the-ACC bag.ACC
'I gave Petros the bag.'
b. Edho-sa tin tsanda tu Petr-u
give-ACT.PST.1SG the bag.ACC the Petros-GEN
'I gave Petros the bag.'

More importantly, the $\mathrm{DO}>\mathrm{IO}$ order presents evidence that it involves a re-ordering of the DO across the IO not feeding binding. This is shown by e.g. the data in (96) where the IO can license a reciprocal in the DO position in the IO $>$ DO permutation (Barss and Lasnik 1986; Larson 1988), while the DO cannot license a reciprocal in the IO position in the DO>IO permutation (Anagnostopoulou 2003:137-143):
a. Estil-a
tis mia-s
mitera-s
ton jio
send-ACT.PST.1SG the one-GEN mother-GEN the son.ACC
tis ali-s
the other-GEN
'I sent each mother the other's son.'
b. *Estila ton ena jio tis mitera-s tu al-u send-ACT.PST.1SG the one son.ACC the mother-GEN the other-GEN 'I sent each son (to) the other's mother.'

\footnotetext{
${ }^{54}$ Note that there is at least one DOM-language providing evidence that there is no correlation between overt case-marking and movement to a VP-external site, even though the relevant diagnostic reported for this language involves placement of DOs relative to VP-adverbs rather than IOs. The language under discussion is Kannada, an SOV Dravidian language discussed in detail in Lidz (2006); see also Kalin and Weisser (2019) for evidence against Movement-Based approaches towards DOM for nine out of eleven languages from five language families based on asymmetric DOM in coordination.
} 
Finally, SMG does provide evidence that movement to the edge of spell-out domains is a precondition for the assignment of dependent accusative. This happens in ECMtype configurations, where accusative subjects move at least to the edge of subjunctive CPs and even higher, obligatorily preceding matrix adverbials, unlike nominative subjects (Kotzoglou and Papangeli 2007). If vP in (90) and (91) is also a spell-out domain just like subjunctive CPs, we would expect the DO to obligatorily occur higher than the IO in SMG ditransitives. But the evidence reviewed above suggests otherwise. We conclude that the vP in (90) and (91) is not a spell-out domain in Greek, and that the DO is accessible to the EA without moving to the edge of the vP. ${ }^{55}$ The differences in the timing of dependent dative assignment and dependent accusative assignment which derive the (un)-availability of case alternations in passives with genitive vs. accusative arguments can be accounted for in terms of the hypothesis that the dative rule applies at $\mathrm{vP}$ and the accusative rule applies at $\mathrm{TP}$, as stated in definitions (24) and (80). Crucially, however, the fact that the vP is the domain of application of the dative rule (24) does not follow from its status as a spell-out domain in SMG.

\subsection{Northern Greek, English, a parametrized dative rule, and a partial typology of ditransitives}

We now turn to NG which has two accusatives on the IO and the DO in ditransitives, as has been shown by the data in (10), here repeated. The obvious question posed by this construction is what type of accusative case is assigned to the IO and the DO, respectively. give-ACT.PST.1sG the Petros.ACC a(n) ice cream.ACC 'I gave Petros an ice cream.'
a. Edho-sa ton Petro ena paghoto
b. Tha se ftia-kso ena paghoto
FUT you.CL.ACC make-ACT.PFV.1SG a(n) ice cream.ACC 'I will make you an ice cream.'

It has already been mentioned that as far as case alternations are concerned, NG behaves similarly to SMG: the accusative IO is not allowed to alternate with nominative, see (12), repeated here, which is sharply ungrammatical in NG just like SMG.
*O Petr-os
do-thike
ena pagoto
the Petros.NOM give-NACT.PST.3SG an ice cream.ACC
'Petros was given an ice cream.'

On the other hand, the accusative DO in (10) is allowed to alternate with nominative in NG similarly to SMG when the IO is 1 st and 2 nd person: ${ }^{56}$

\footnotetext{
${ }^{55} \mathrm{Cf}$. Keine (2016) who argues against $\mathrm{vP}$ phases quite generally, on the basis of selective opacity, nonlocal agreement and processing evidence from different languages.

${ }^{56}$ This is an interesting difference between the two varieties of Greek that will not concern us here. In SMG the DO can undergo passivization regardless of the person of the IO, provided that the IO is a clitic or a clitic doubled DP. In NG, on the other hand, the IO must be 1st or 2nd person, as shown in (97).
} 


To pagoto me/se/*?ton
the ice cream.NOM me.CL.ACC/you.CL.ACC/*him.CL.ACC
do-thike
give-NACT.PST.3SG
'The ice cream was given me/you.'

The ungrammaticality of (12) and the grammaticality of (97) (modulo a person effect, see footnote 56) clearly suggest that the NG construction cannot be analyzed as a double accusative construction of the type found in SMG with "teach," "pay" and "serve," where accusative IOs freely undergo Acc-Nom alternations in passives.

We are led to conclude that NG ditransitives must be analyzed essentially like their SMG counterparts: they are regular applicatives where the IO receives dependent case 'upwards,' in opposition to the lower DO, and the DO receives regular dependent accusative 'downwards,' in opposition to the higher EA. In other words, we are led to propose that dependent accusative on the IO in NG is subject to rule (98a), which is identical to the dependent genitive rule (98b) in SMG, except for the case value of U. Both (98a) and (98b) are instantiations of the dependent dative rule (24), repeated below. The dative rule applies in both dialects, regardless of the specific case morphology, which can thus be seen as a rather superficial reflex of history, associated with the loss of dative morphology and its replacement with either accusative or genitive morphology as a result of syncretism. ${ }^{57}$

a. If XP c-commands $\mathrm{ZP}$ in $\mathrm{vP}$, then assign $U$ (accusative) to $\mathrm{XP}=\mathrm{NG}$

b. If XP c-commands $\mathrm{ZP}$ in $\mathrm{vP}$, then assign $U$ (genitive) to $\mathrm{XP}=\mathrm{SMG}$

\section{Dependent dative case rule in $M G$}

\section{If XP c-commands ZP in VP, then assign $\mathrm{U}$ (dative) to XP}

To the extent that it is correct to postulate dependent case rules for English (they clearly apply to pronouns which bear overt case morphology, while this is less straightforward for DPs which are morphologically unmarked for case), the fact that

When the IO is 3rd person, speakers resort to the SMG construction with a genitive IO, as in (92). See Anagnostopoulou (2018), for discussion of the 1st/2nd vs. 3rd asymmetry in (97) which is also found in NG transitive clitic clusters and is analyzed as a spurious $s e$-type dissimilation effect arising because the two 3rd person objects bear identical case morphology (see Bonet 1991; Nevins 2007, i.a.), inviting a Distinctness analysis at the clitic/agreement level in terms of sensitivity to person features.

${ }^{57}$ According to an anonymous $N L L T$ reviewer, replacement of genitive by accusative is not total and may vary in the various varieties of Northern Greek or be subject to sociopragmatic factors. There are also instances in which NG speakers use the genitive the same way as SMG speakers. For example, the accusative case marking on the Experiencer argument is not normally found with dyadic unaccusative predicates such as xriazete 'I need', or sensation verbs such as kriono 'I feel cold'. According to the reviewer, accusative case is obligatory only with goal arguments and optional with experiencer arguments, subject to speaker variation. The appearance of the genitive in these constructions cannot be attributed to SMG influence, because it can be found with older speakers and texts. It may be argued that the distribution of the accusative was reinforced by the linguistic repertoires of the refugees from Asia Minor (in Asia Minor Greek, e.g. Pontic, Pharasiot, Cappadocian, the distribution of genitive is scarce and it has been completely replaced by accusative in the relevant examples), who immigrated in large numbers in the northern parts of Greece after the population exchange with Turkey in 1924. 
English IOs enter case alternations in passives, as seen in (99), suggests that they are subject to the standard dependent accusative case rule in (80), written here as (100):

a. I gave him a book.

b. He was given a book.

Dependent accusative case rule:

$$
\text { If XP c-commands } \mathrm{ZP} \text { in } \mathrm{TP} \text {, then assign } U \text { (accusative) to } \mathrm{ZP}=\text { English }
$$

In other words, English lacks a dative rule applying in VP, unlike SMG and NG. This leads to a parametrization of which dependent case is valuated first in ditransitives. In $\mathrm{NG}$, dependent case assignment proceeds exactly as in SMG. At vP, the case of the IO is valuated as accusative in opposition to the lower DO. At TP the DO is then assigned dependent accusative in opposition to the EA. The IO is case marked before the DO as a result of the fact that rule (24) applies in vP while rule $(80) /(100)$ applies in TP. In English, on the other hand, the reverse holds: the DO is case marked before the IO. In the absence of a dative rule and under the assumption that the derivation proceeds bottom up, the DO is assigned dependent accusative first, in opposition to the IO, and then the IO is assigned dependent accusative in opposition to the higher EA. As a result of this difference in the order of case assignment which derives from the parametric (un-)availability of the dative rule in the two languages, only the DO may undergo passivization in NG under the appropriate conditions (when the IO is 1st or 2nd person), similarly to the situation in SMG, while it is the IO that alternates in English.

\subsection{Dat-Nom and Gen-Nom alternations in passives: MG vs. CG}

Our proposal has implications for the understanding of Dat-Nom and Gen-Nom alternations in passives. We have seen that Gen-Nom alternations are impossible in SMG; the language only permits Acc-Nom alternations (i.e. theme-passivization), provided that the intervening goal undergoes cliticization/clitic doubling. On the other hand, Alexiadou et al. (2014) and Anagnostopoulou and Sevdali (2015) point out that DatNom and Gen-Nom alternations were possible in CG passives, and the data below illustrate this (examples (9), (12), (19) and (23) from Anagnostopoulou and Sevdali 2015):

\section{DAT-NOM ALTERNATIONS IN MONOTRANSITIVES:}

a. Athēnai-oi epibouleu-ousin hēm-in

Athenians-NOM betray-ACT.PRS. 3SG us-DAT

'The Athenians are betraying us.'

b. Hèm-eis hup' Athēnai-ōn epibouleu-ometha

we-NOM by Athenians-GEN betray-NACT.PRS.1PL

'We are betrayed by the Athenians.' (Thucydides, Historia I:82. 1)

(102) GEN-NOM ALTERNATIONS IN MONOTRANSITIVES:

a. Katapsēphēz-ō tin-os

condemn-ACT.PRS.1SG someone-GEN

'I condemn someone.' 
b. Ekeino-s katepsēphis-thē

he-NOM condemn-NACT.AOR.3SG

'He was condemned.'

(Xenophon, Historia V:2. 36)

DAT-NOM ALTERNATIONS IN DITRANSITIVES:

a. Active: ACC-DAT

All-o ti meiz-on hum-in epitaks-ousin

something.else-ACC bigger-ACC you-DAT order-ACT.FUT.3PL

'They will order you to do something else bigger/greater.'

b. Passivized: ACC-NOM

All-o ti meiz-on hum-eis epitakhthēs-esthe

something.else-ACC bigger-ACC you-NOM order-NACT.FUT.2PL

'You will be ordered to do something else, bigger.'

(Thucydides, Historia I:140. 5)

GEN-NOM ALTERNATIONS IN DITRANSITIVES:

a. Active: GEN-ACC

Apetem-on tōn stratēg-ōn tas kephal-as

cut.off-ACT.AOR.3PL the generals-GEN the heads-ACC

'They cut the heads from the generals.'

b. Passivized: NOM-ACC

Hoi stratēg-oi apetmēth-ēsan tas kephal-as

the generals-NOM cut.off-NACT.AOR.3PL the heads-ACC

'The generals were beheaded./The generals had their heads cut off.'

(Xenophon, Anabasis II: 6. 29)

The two stages of Greek show exactly the reverse patterns from what are typically assumed to characterize the distinction between structural and lexical/inherent case. SMG has dependent (i.e. what would correspond to structural) genitive case which is not allowed to alternate with nominative in passives, while $\mathrm{CG}$ had lexical/inherent (i.e. the counterpart of non-structural) dative and genitive case which were allowed to alternate with nominative in passives. Note that in the present approach, the traditional dichotomy between inherent vs. structural case doesn't hold, and therefore this terminology is no longer helpful.

Starting from the SMG pattern, we have argued that the ungrammaticality of (12) as opposed to (92) is a consequence of the dependent genitive case rule (24) which crucially applies in vP. ${ }^{58}$ As we discussed in detail in Sects. 3 and 4, the case feature

\footnotetext{
${ }^{58}$ An anonymous reviewer asks how we can be confident that the unavailability of (12) is due to case, rather than due to some constraint blocking extraction of goals out of DOCs to subject position. An immediate reply could be that there is no problem for genitive arguments to occur in the preverbal position, as shown by the grammaticality of examples like (i) which provide evidence that that there is no constraint blocking goals from appearing in a position preceding the verb instead of themes. Compare (i) to (92) in the main text:
}

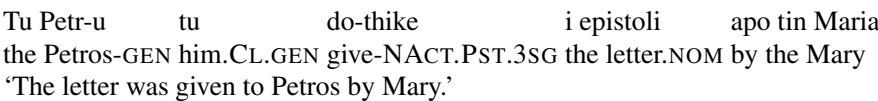


of the IO is valued as Gen by rule (24) since the vP includes a c-commanded DO that is caseless. This happens regardless of whether Voice is active (ACT) having a specifier or passive (PASS) lacking one. In this respect, SMG behaves like Sakha which has also been argued to have dependent dative case. In Sakha, as in MG, themes are passivized and goals remain dative (Baker and Vinokurova 2010, ex. (29)):

$$
\begin{aligned}
& \text { Suruk Masha-qa yyt-ylyn-na } \\
& \text { letter Masha-DAT send-PASS-PST.3SG } \\
& \text { 'The letter was sent to Masha.' }
\end{aligned}
$$

It is important to stress at this point that it is not the case that SMG generally lacks Gen-Nom alternations. Section 3 presented extensive evidence for the availability of such alternations with the verbs 'aresi' and 'arki' (Sect. 3.2. examples (29) and (30b)), with idioms (Sect. 3.3., examples (42)) and with unaccusative sensation predicates (Sect. 3.5, examples (51)-(52)). In all of these cases, the higher argument receives dependent genitive in opposition to a lower DP theme, and receives environmentsensitive nominative when the lower argument is realized as a PP, or when the DPclitic is missing, or with monadic verbs. We conclude that Gen-Nom alternations in SMG are sensitive to the presence vs. absence of a lower theme because dependent genitive is assigned in opposition to a lower DP in the vP domain. On the other hand, the active-passive alternation is an alternation in the presence vs. absence of a higher $D P$ argument, and dependent genitive case is insensitive to the presence of a higher argument, unlike dependent accusative to the theme which is sensitive to it. Looking at the behavior of IOs in passives will therefore not be informative as to whether the IOs in question have lexically governed case or whether they have dependent case. In languages with the dative rule (24) we expect Gen-Nom alternations to arise in environments other than passives. Of course, the behavior of IOs in passives is still important in the SMG double accusative constructions where the IO is assigned case in opposition to the higher EA and in languages like English which lack a dative rule, i.e. in cases where IOs are assigned case in opposition to a higher DP falling under rule $(80) /(100)$.

The more general conclusion we would like to draw from these facts is that, unlike longstanding standard practice, it is misleading to decide on the status of dative and genitive DPs in a particular language only by looking at their behavior in passives: if they are assigned dependent case "upwards" in the VP-domain subject to rule (24), then they are not expected to alternate with nominative in passives (since they are insensitive to the presence of a higher argument), while at the same time they will be alternating with nominative or accusative depending on the presence vs. absence of a lower argument, whether the lower argument is a DP vs. PP, or in causatives (depending on whether the embedded predicate is transitive or intransitive). This variability

The more intricate issue relating to the reviewer's point is whether the preverbal position in e.g. (i) or (92) indeed qualifies as a subject position. For example, Alexiadou and Anagnostopoulou (1998) and others argue that the preverbal position in SMG is a Clitic Left Dislocated position because the EPP is satisfied by verb-raising in this language. And even if the preverbal position is a subject position (this is controversial in the literature on Greek), it is fairly uncontroversial that nominative is not assigned in that position. Due to the pro-drop, VSO nature of SMG, nominative freely occurs vP-internally, on subjects in transitive VSO/VOS sentences (Alexiadou and Anagnostopoulou 2001) and on objects in passives and unaccusatives. 
in the availability of Dat-Nom and Gen-Nom alternations within a language, depending on the specific syntactic configuration dative and genitive arguments occur in (whether a higher vs. a lower argument is present/absent), is a strong argument in favor of a dependent case approach towards case-alternations and against alternative more traditional approaches in terms of Case absorption.

Let us now turn to the CG pattern of alternations. The core observation we will build on is that all verbs in the examples (101)-(104) above, and many of the verbs that allow passivization of dative/genitive IOs in CG are prefixed, as shown in (106) (cf. also Michelioudakis 2012):
a. epi-bouleuo-metha 'be betrayed'
b. kat-epsēphis-thē 'be condemned'
c. epi-takhthēs-esthē 'be ordered'
d. ap-etmēth-ēsan 'be cut off'

Crucially, these prefixes are homophonous to the corresponding prepositions which retain their case-assigning properties when they are prefixed to the verbs: when the prepositions assign dative to their complements, the corresponding prefixed verbs assign dative to their objects and when the prepositions assign genitive to their complements, the corresponding prefixed verbs assign genitive to their objects. Strikingly, all prefixed verbs showing Dat $>$ Nom and Dat $>$ Gen alternations in CG, e.g. the verbs in (106), have case assigning properties that match those of the corresponding free-standing preposition. On the other hand, the prefixed verbs that disallow Dat $>$ Nom and Gen $>$ Nom alternations have case assigning properties that do not match those of the corresponding free-standing preposition. The latter case is exemplified by verbs such as em-pimplèmi 'fill in', apo-stellō 'send', and ex-isō̄ 'equate'. In these cases, the prefixes en-apo- and $e k$ - assign dative, genitive and genitive, respectively, when they are free-standing prepositions, but do not take arguments in the same case when they act as prefixes (empimplèmi 'fill in' takes a genitive argument, apostellō 'send' takes a dative argument, and exiso $\bar{o}$ 'equate' takes a dative argument again). ${ }^{59}$ Building on this key observation and following Alexiadou

\footnotetext{
${ }^{59}$ There are only two exceptions to the generalization that Dat $>$ Nom and Gen $>$ Nom alternations under passivization are only possible with verbs containing prefixes that retain the case assigning capacities of the corresponding free-standing prepositions. The verbs dia-tassō 'order, appoint' and pro-mēnūo 'predict' form Acc-Dat ditransitives, whose datives alternate with nominatives under passivization, but free-standing preposition dia normally assigns accusative or genitive, while free-standing preposition pro assigns genitive (Bortone 2010). Nevertheless, we believe that these are only apparent exceptions. In the case of pro-mēnuō, the prefix pro really is not a preposition, instead it is the adverbial element that is also found in the latinate root or pre-dict, and it means 'before.' This element is not a case assigning preposition, and the dative is not directly related to this prefix. Instead, what we think is going on is that promennuo takes a dative IO by analogy to its unprefixed version mēnuō, whose dative is related to the role of addressee. As a matter of fact, all derivatives of mēnū take dative IOs and allow these datives to alternate with nominatives under passivization. A similar story can be told for diatassō, where here again the dative on the IO of this verb is the same as the one found in its corresponding root tasso $\bar{o}$ and all its derivatives. The prefix diadoes not often appear as a free-standing element, except in Homer according to Liddel Scott Jones, where it means 'throughout,' and the dia in diatassō seems to have a distributive meaning more than anything. The datives of verbs like diatass $\bar{o}$ and tassō but also the rest of the verbs of this semantic class that stem from the tassō root like epitass $\bar{o}$ and prostassō 'order' are addressees, related lexically to these predicates, and are not assigned individually by prefixes. We want to thank Dionysios Mertyris (p.c.) for discussion around this set of data.
} 
et al. (2014) we propose that genitives and datives in CG which have been seen to have lexically governed case falling under (21a) are always contained within PPs, overt, as in the prefixed examples discussed here, or covert with non-prefixal verbs (see, among others, Bittner and Hale 1996; Rezac 2008; Caha 2009; Pesetsky 2013; Baker 2015 that dative, genitive, instrumental, ablative arguments are hidden PPs). Prefixal verbs in CG like the ones in (106) are formed by P(reposition)-incorporation of the prepositions introducing the dative and genitive objects. In principle, PPs are phases, and, therefore, DPs contained within them are inaccessible to operations triggered by higher heads; this makes lexically governed datives opaque to operations like Agree and Move. However, there are strategies by which such PPs become transparent, as discussed in e.g. Rezac (2008) for different dialects of Basque. One major strategy leading to the transparency of dative and genitive objects is $\mathrm{P}$ incorporation into a higher head, the complex V-v-Voice. The phase-lifting effect of $\mathrm{P}$-incorporation follows from the hypothesis that head-movement of certain phase heads extends the phase to the higher projection, as proposed by den Dikken (2007), Gallego (2006, 2010), Gallego and Uriagereka (2006), see also Bobaljik and Wurmbrand (2013), in the spirit of Baker's (1988) Government Transparency Corollary. P-incorporation in CG thus makes the relevant PPs transparent, and the dative and genitive objects are allowed to passivize, as shown in (101b)-(104b) above.

The next step is to explain why transparent dative and genitive CG objects do not preserve their case and are allowed to alternate with nominative in passives despite the fact that they bear idiosyncratic/thematic, i.e. "lexically governed" case in the sense of (21a). We cannot provide a complete answer to this question here, as it would require a thorough investigation of the verbs that allow and disallow passivization in CG (see Anagnostopoulou et al. 2018 for an initial classification of the relevant verbs based on a corpus study), but we will briefly mention two options that could be explored.

One possibility would be to follow Anagnostopoulou and Sevdali (2015) who argue that alternating datives and genitives in CG are, in fact, special instances of dependent cases assigned in opposition to a higher argument. Anagnostopoulou and Sevdali propose that CG datives and genitives fall under the rules in (107) ((33) in the original paper), which in the present system would be seen as special instances of the dependent accusative rule (80), supplemented by further information on particular verbs, prepositions and, perhaps also, applicative heads introducing the relevant DPs: 60

a. [uCASE] $\rightarrow$ NOM iff the DP is not c-commanded by another structurally Case-marked DP (within the domain of finite T).

\footnotetext{
${ }^{60}$ This proposal is in line with what an anonymous reviewer also suggests. According to the reviewer, when datives and genitives are linked to the semantics of predicates (and to a lesser extent theta roles) like in CG "structural cases are [not] assigned uniformly by a structure regardless of the particular lexical items in those structures" but instead there is a rule that assigns genitives and datives with specific verbs and accusative is an elsewhere case. This is what Anangnostopoulou and Sevdali (2015) have argued in their rule (33) (107) in the main text above) for case spell out in CG which essentially treats datives and genitives as more specific forms of accusative, and specified as such in the context of specific verbs and prepositions. While this is a possible way to interpret the facts, such a proposal still leaves open the question of how to characterize the shift from dative and genitive as dependent cases 'downward' to genitive (and accusative in NG) as dependent cases 'upward.'
} 
b. [uCASE] $\rightarrow$ DAT iff the DP is c-commanded by another structurally Case-marked DP within the domain of finite T and is sister to verb1, verb2, verb3, preposition1, preposition2...

c. [uCASE] $\rightarrow$ DAT iff the DP is c-commanded by another structurally Case-marked DP within the domain of finite $\mathrm{T}$ and is $\mathrm{m}$-commanded by applicative v1 (benefactive/goal).

d. [uCASE] $\rightarrow$ GEN iff the DP is c-commanded by another structurally Case-marked DP within the domain of finite T and is sister to verb4, verb5, verb6, preposition3, preposition4...

e. [uCASE] $\rightarrow$ GEN iff the DP is c-commanded by another structurally Case-marked DP within the domain of finite $\mathrm{T}$ and is $\mathrm{m}$-commanded by applicative v2 (source/possession).

f. [uCASE] $\rightarrow$ ACC iff the DP is c-commanded by another structurally Case-marked DP within the domain of finite T.

The rules in (107) express the idea that DAT and GEN are more specific forms than ACC. They are conditioned by the same environment that conditions accusative assignment, with an additional condition that takes into account the closest relevant verb or applicative $\mathrm{v}$ or P. Being more specific, dative and genitive block the assignment of accusative, which is the elsewhere case assigned to objects whenever the conditions for the more specific forms do not apply. Thus, (107) on the one hand expresses the 'irregular' distribution of dative and genitive, as opposed to the regular distribution of accusative objects in actives, and on the other hand captures the fact that all three cases alternate with nominatives in passives.

Note that, if we go with this analysis, it will be crucial to limit the rules in (107) only to those datives and genitives that are allowed to alternate in passives, after $\mathrm{P}$-incorporation takes place. There are also cases where this is impossible. For example, there are prefixed verbs, whose prefix case-assigning properties match those of the corresponding free-standing preposition and whose dative arguments do not alternate with nominatives in passives (e.g. apokaluptō 'reveal', apaggellō 'report' and hupagoreuō 'dictate' with non-alternating datives (among others), and katadikazō 'condemn' and apostere $\bar{o}$ 'deprive' with non-alternating genitives (among others)). Moreover, unlike SMG which never allows a genitive argument to surface in the absence of a lower DP argument, CG did allow dative arguments to surface in the absence of a higher nominative argument, as shown in (108) with melei 'take care of':

$$
\begin{aligned}
& \text { Pant-ōn emel-en aut-ōi } \\
& \text { all things-GEN take.care.of-ACT.PST.IMP.3SG he.DAT }
\end{aligned}
$$

"He took care of everything." ～(Xenophon, Apologia IV:7.1)

An alternative possibility would be to propose that in passivization environments with P-incorporation, dative and genitive arguments acquire an additional nominative case in a case-stacking analysis (Richards 2013). This seems incom- 
patible with the view of nominative as environment-sensitive case if environmentsensitive case is seen as last resort case assigned only to case-less DPs. Following Baker $(2008,2015)$, we could therefore assume that nominative case in CG is always assigned under Agree with finite $\mathrm{T}$ in $\mathrm{CG}$, a proposal supported by the observation that there is a strong one-to-one relationship between nominative case and finite agreement in the language. ${ }^{61}$ As discussed in Sevdali (2007), overt subjects obligatorily bear accusative morphology in non-ECM, non object-control infinitival constructions called "Accusativus Cum Infinitivo" in the literature. In active sentences, the internal argument is assigned genitive or dative by an overt or covert P, which is incorporated into V, as illustrated in (109). Voice introduces the EA and T enters Agree with it, resulting in nominative case on the subject:

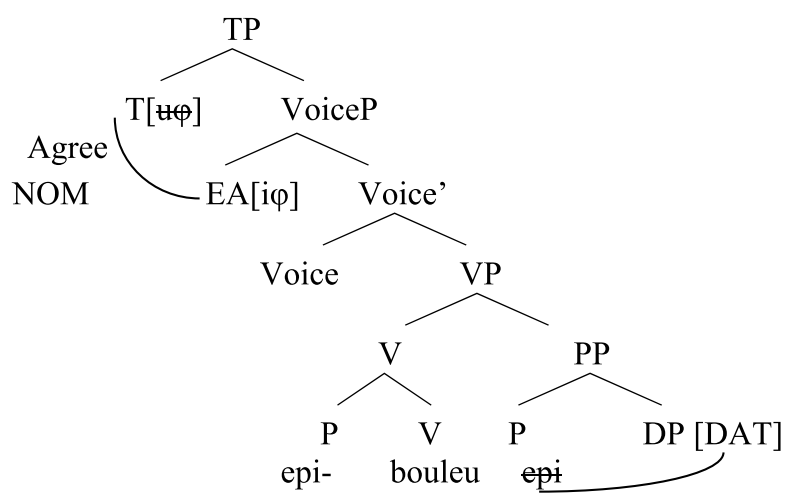

In passives, Voice does not introduce an EA, P incorporation makes the PP transparent and T may enter Agree with the DP object, resulting in nominative case, as depicted in (111). The easiest way to deal with this kind of alternation is to propose that nominative case is 'stacked' on top of the dative in (111) and only the outermost nominative case is spelled out, following the hypothesis that CG only allows a single case value on nominals, as stated in the Parameter in (110) (Baker 2015:284; see also Pesetsky 2013):

(110) The case feature associated with nominal X can have a single value (Shipibo, $C G . .$. ) or it can have a set of values (Quechua, Korean, some Australian languages).

\footnotetext{
${ }^{61} \mathrm{An}$ anonymous reviewer points out that this state of affairs is also compatible with an analysis where agreement is only able to target nominative marked noun phrases (Bobaljik 2008; cf. Levin and Preminger's 2015 reanalysis of Sakha facts analyzed in Baker and Vinokurova's 2010 in terms of Agree). It seems to us though that it is difficult to handle the availability of Dat-Nom and Gen-Nom alternations in CG if we assume that Nominative is an environment-sensitive case in this language. There are reasons to assume that environment-sensitive nominative is assigned as a last resort to otherwise caseless DPs. In the CG cases we discuss now, however, the relevant DPs are not caseless.
} 
(111)

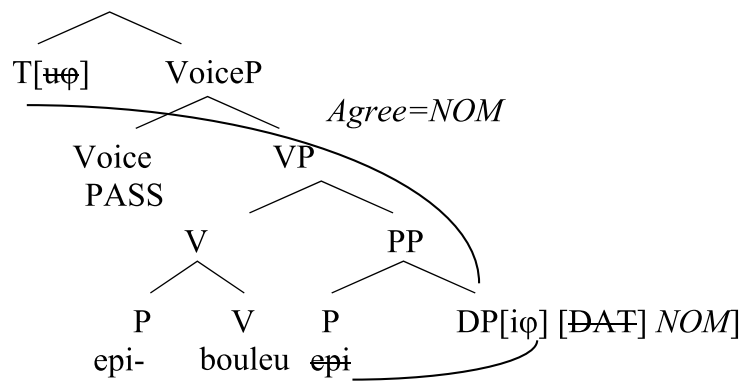

Independent evidence that CG freely allows for a lower case to be overwritten by a higher one is provided by the phenomenon of Case Attraction in free relative clauses whereby a wh-phrase assigned one case in the relative-internal position surfaces with the higher one assigned to the entire free-relative clause if the higher case is more marked than the lower one (Groos and van Riemsdijk 1981; Grosu 1994; Humbert 1960; Smyth 1956; Grimm 2007; Kakarikos 2014, ex. (5)-(8)): ${ }^{62}$

Some case attraction patterns in $C G$

Genitive vs. Accusative $\rightarrow$ Genitive
a. amelē-sas
ōn (for: a-ACC) me
having neglected-PTCP.PFV.M.NOM what-GEN I.ACC
dh-ei prattein
must-3SG do-INF
'having neglected what I ought to do'
(Xen. Cyr. 5.1.8.)

Dative vs. Nominative $\rightarrow$ Dative

b. tout-o omoion esti ōi (for: o-NOM) nun dhe kai this-ACC like-ACC is-3SG which-DAT now then and elegh-eto

say-NACT.3SG

'this is like what was said just now'

(Pl. Phaedr. 69a)

Dative vs. Accusative $\rightarrow$ Dative

c. pan to tek-on troph-ēn ekh-ei $\overline{\mathbf{o}}$ (for: o-ACC) an any the parent-NOM food ACC have-3SG what-DAT ever tek-ē

give-birth-3SG

'any parent provides food to whoever he gives birth' (Pl. Men. 237e)

At the same time, however, the Case Attraction facts exemplified above are not amenable to exactly the same analysis as the passivization facts discussed here for one key reason: namely that in Classical Greek when there is case conflict in free relatives this conflict is always resolved in favor of the most marked case, no matter whether this is the higher or the lower one, resulting sometimes in inverse attraction situations (see Schwyzer and Debrunner 1950 and Probert 2015 for details and

${ }^{62}$ We thank an anonymous reviewer for pointing out to us the relevance of the CG case attraction facts. 
data). ${ }^{63}$ Following Caha (2009) and Pesetsky (2013) we can tentatively assume that it is, in principle, possible for a higher unmarked case to override a lower marked one in syntax, and that this option is instantiated in the chains formed in CG passives. Perhaps, this is related to the fact that the CG nominative is unusual in that NOM is not morphologically unmarked compared to other cases, and this helps it to overwrite in a way that other languages would resist. ${ }^{64}$ On the other hand, in CG free relatives it is always the more marked case that wins, regardless of whether it is higher or lower, for reasons having to do with the more local resolution of case-morphology conflicts at $P F$.

\section{Conclusions}

This paper provided evidence that there are two modes of dative and genitive case assignment on the basis of the properties of dative and genitive arguments in two stages of Greek. Classical Greek provides evidence that dative and genitive were lexically governed cases which must be analyzed as prepositional cases. On the other hand, Standard Modern Greek has dependent genitive case in the vP domain. This core difference not only offers a principled explanation for the different distribution of nonaccusative objects in transitives and ditransitives in CG and SMG. It also explains: a) A range of systematic properties of SMG, such as the availability of Gen-Nom alternations with several predicates when a lower argument is absent or realized as a PP, but not in passives. $b$ ) The genitive vs. accusative realization of goals in the absence of a lower argument, when a lower argument is realized as a PP and in theme incorporation contexts (in contrast to $\mathrm{CG}$ where theme-incorporation does not affect the dative case on goals). c) The grammaticality of high genitive applicatives with static predicates and unaccusatives but not with unergatives. $d$ ) The sensitivity of higher arguments to the properties of lower ones (definiteness, PP vs. DP realization and heaviness) in causatives formed with 'learn,' aspectual verbs and teach-verbs. We investigated dependent genitive and dependent accusative case in SMG and we argued that their distribution can be accounted for under the hypothesis that genitive is dependent case assigned in opposition to a lower DP argument, while accusative is assigned in opposition to a higher argument. The further hypotheses that (i) genitive is dependent case upwards in the vP domain, (ii) accusative is dependent case downwards in the TP domain and (iii) dependent case is assigned in opposition to a DP that has not yet received case is sufficient to account for the SMG data, while at the same time explaining certain, otherwise mysterious, cross-linguistic differences, such as the sensitivity of SMG possessors vs. Hebrew and German ones to PP possessed arguments in possessor raising constructions. Finally, the variation we find in the behavior of IO DPs in NG, English and SMG as far as passivization is concerned led us to propose that these languages differ in whether dependent objective case (accusative or dative/genitive) is assigned first on the IO or the DO argument, which in turn, depends on the availability of a dependent dative rule in vP.

\footnotetext{
${ }^{63}$ We thank an anonymous reviewer for input on this point.

${ }^{64}$ We thank Mark Baker (p.c.) for suggesting this possibility to us.
} 
We discussed the implications of the present approach for the syntax of Dat-Nom and Gen-Nom alternations which were available in CG and are unavailable in SMG. For SMG, the lack of Gen-Nom alternations follows from the definition of genitive as dependent case upwards. For CG, the availability of such alternations is crucially linked to P-Incorporation which makes dative and genitive PPs transparent to further morpho-syntactic processes. Prefixal verbs in CG have been shown to provide independent evidence for the process of P-Incorporation and its link to passivization. We also suggested two potential ways of interpreting the Dat-Nom and Gen-Nom alternations in $\mathrm{CG}$ passives.

Beyond the contribution to the empirical domain of Greek the papers offers a theoretical contribution to Case-theory that can be summarized as follows: First, SMG provides an argument that genitive/dative is dependent case, because it shows that genitive is a completely regular case in ditransitives, blindly marking all IOs independently of their thematic role provided that the core configuration for dependent genitive assignment is met, namely a lower DP argument with an unvalued case feature is present in the vP domain. Second, Greek offers a powerful set of arguments against treating case alternations in terms of mechanisms like Case absorption. Third, the SMG vs. CG puzzle with respect to the passivizability of objects shows that passivization is not always an adequate tool for diagnosing the 'structural' vs. 'inherent case' status of arguments. The directionality of dependent case assignment, the nature of nominative case, the option of lifting the phasal status of PPs via P-Incorporation, and perhaps also whether a language allows for a lower marked case feature to be overwritten by a higher unmarked one (or, alternatively, the nature of lexical dative and genitive as a special instance of dependent case downwards) play a crucial role. Fourth, the comparison of double accusative constructions and genitive constructions in SMG, on the one hand, and of ditransitives in SMG, NG and English, on the other, led to a new approach towards the variation and parametrization of dative and accusative case in ditransitives and a novel typology of ditransitives and ditransitivepassives.

Overall, the present system provides new insights into the fundamental properties of a phenomenon that very clearly has both a morphological and an abstract syntactic side. Concerning the morphology-syntax relationship, the study of morphological exponence has been seen to offer an important window into the mechanics of the abstract syntactic principles involved, but morphology itself turned out to be epiphenomenal in several ways. For one, even though the co-existence of dative with genitive morphology in CG provided a crucial key towards analyzing datives and genitives as PPs, in contrast to SMG genitives which qualify as DPs, it is the PP vs. DP difference that ultimately determines the distribution and passivizability of non-accusative objects in the two stages of Greek. Moreover, the comparison of NG to SMG has led to the conclusion that there is no syntactic difference between the two dialects as far as IO-passivization is concerned, regardless of the accusative vs. genitive case morphology of IOs, because in both dialects IOs are assigned dependent case in exactly the same way, falling under the dependent dative rule in vP. Finally, the comparison of NG to English showed that the parametric availability of a dependent dative rule in vP further determines the (un-)availability of IO-passivization, regardless of the fact that both objects bear identical case morphology in both languages. 
Acknowledgements This paper has occupied us for quite some time now and the people that have helped us along the way are too numerous to mention individually. However, we want to thank the audiences at GLOW 2016, DiGS 17 (17th Diachronic Generative Syntax Conference, University of Iceland), David Pesetsky@60 Panel on Case, the International Conference of Greek Linguistics (ICGL 13 at the University of Westminster, London and ICGL 14 at the University of Patras) and the Linguistics Seminar Series at Ulster University where earlier versions of this work have been presented, for very useful comments. We want to gratefully acknowledge the support of the Arts and Humanities Research Council in funding the project "Investigating variation and change: Case in Diachrony" (award number AH/P006612/1). We also want to thank Morgan Macleod and especially Dionysios Mertyris for their contribution to the project. Finally, we want to thank Mark Baker, Julie Anne Legate, as well as five anonymous reviewers for NLLT whose comments significantly improved this paper. All errors, of course, remain our own.

Publisher's Note Springer Nature remains neutral with regard to jurisdictional claims in published maps and institutional affiliations.

Open Access This article is licensed under a Creative Commons Attribution 4.0 International License, which permits use, sharing, adaptation, distribution and reproduction in any medium or format, as long as you give appropriate credit to the original author(s) and the source, provide a link to the Creative Commons licence, and indicate if changes were made. The images or other third party material in this article are included in the article's Creative Commons licence, unless indicated otherwise in a credit line to the material. If material is not included in the article's Creative Commons licence and your intended use is not permitted by statutory regulation or exceeds the permitted use, you will need to obtain permission directly from the copyright holder. To view a copy of this licence, visit http://creativecommons.org/licenses/by/4.0/.

\section{References}

Aissen, Judith. 2003. Differential object marking: Iconicity vs. economy. Natural Language and Linguistic Theory 21(3): 435-483.

Alexiadou, Artemis. 2001. Functional structure in nominals. Nominalization and ergativity. Amsterdam: Benjamins.

Alexiadou, Artemis. 2014. Roots don't take complements. Theoretical Linguistics 40(3/4): 287-297.

Alexiadou, Artemis. 2016. DP internal (clitic) doubling. In 7th Nereus international workshop: clitic Doubling and other issues of the syntax/semantic interface in Romance DPs, 128, eds. Susann Fischer and Mario Navarro Arbeitspapier, 1-10. Available at https://kops.uni-konstanz.de/bitstream/handle/ 123456789/35916/Fischer_0-372560.pdf?sequence=3\&isAllowed=y. Accessed 24 January 2020.

Alexiadou, Artemis. 2018. Able adjectives and the syntax of psych verbs. Glossa: A Journal of General Linguistics 3(1): 74. https://doi.org/10.5334/gjgl.498.

Alexiadou, Artemis, and Elena Anagnostopoulou. 1998. Parametrizing AGR: Word order, V-movement and EPP-checking. Natural Language and Linguistic Theory 16(3): 491-539.

Alexiadou, Artemis, and Elena Anagnostopoulou. 2001. The subject-in-situ generalization and the role of case in driving computations. Linguistic Inquiry 32(2): 193-231.

Alexiadou, Artemis, and Elena Anagnostopoulou. 2019. Novel Experiencer-Object verbs and clitic doubling. Syntax 22(2): 116-145.

Alexiadou, Artemis, Elena Anagnostopoulou, and Florian Schäfer. 2006. Properties of anticausatives cross-linguistically. In Phases of interpretation, ed. Mara Frascarelli, 187-212. Berlin: de Gruyter.

Alexiadou, Artemis, Elena Anagnostopoulou, and Florian Schäfer. 2015. External arguments in transitivity alternations: A layering approach. Oxford: Oxford University Press.

Alexiadou, Artemis, Elena Anagnostopoulou, and Christina Sevdali. 2014. Opaque and transparent datives, and how they behave in passives. The Journal of Comparative Germanic Linguistics 17(1): 1-34.

Amberber, Mengistu. 2009. Quirky alternations of transitivity: The case of ingestive predicates. In The Linguistics of Eating and Drinking, ed. John Newman, 45-64. Amsterdam: Benjamins.

Anagnostopoulou, Elena. 1999. On experiencers. In Studies in Greek syntax, eds. Artemis Alexiadou, Geoffrey Horrocks, and Melita Stavrou, 67-93. Dordrecht: Kluwer.

Anagnostopoulou, Elena. 2001. Two classes of double object verbs: The role of zero morphology. In Progress in grammar: Articles at the 20th anniversary of the Comparison of Grammatical Models Group in Tilburg, eds. Marc van Oostendorp, and Elena Anagnostopoulou, Amsterdam: Meertens Institute. 
Anagnostopoulou, Elena. 2003. The syntax of ditransitives: Evidence from clitics. Berlin: de Gruyter.

Anagnostopoulou, Elena. 2005. Cross-linguistic and cross-categorial distribution of datives. In Advances in Greek generative syntax, eds. Melita Stavrou and Arhonto Terzi, 61-126. Amsterdam: Benjamins.

Anagnostopoulou, Elena. 2018. Defective intervention effects in two Greek varieties and their implications for $\varphi$-incorporation as Agree. In Order and structure in syntax II, eds. Michelle Sheehan and Laura R. Bailey. Berlin: Language Science Press.

Anagnostopoulou, Elena, and Christina Sevdali. 2015. Case alterations in Ancient Greek passives and the typology of Case. Language 91(2): 442-481.

Anagnostopoulou, Elena, Dionysios Mertyris, and Christina Sevdali. 2018. A classification of Ancient Greek three-place predicates and the structure of datives and genitives. Paper presented at PlaCiG (On the place of case in Grammar), University of Crete.

Baker, Mark C. 1988. Incorporation: A theory of grammatical function changing. Chicago: University of Chicago Press.

Baker, Mark C. 2008. The syntax of agreement and concord. Cambridge: Cambridge University Press.

Baker, Mark C. 2015. Case. Its principles and its parameters. Cambridge: Cambridge University Press.

Baker, Mark C., and Jonathan David Bobaljik. 2017. On inherent and dependent theories of ergative case. In The Oxford Handbook of Ergativity. Oxford: Oxford University Press.

Baker, Mark C., and Nadya Vinokurova. 2010. Two modalities of case assignment: Case in Sakha. Natural Language and Linguistic Theory 28(3): 593-642.

Barss, Andrew, and Howard Lasnik. 1986. A note on anaphora and double objects. Linguistic Inquiry 17(2): 347-354.

Belletti, Adriana, and Luigi Rizzi. 1988. Psych-verbs and $\theta$-theory. Natural Language and Linguistic Theory 6(3): 291-352.

Bhatt, Rajesh, and Elena Anagnostopoulou. 1996. Object shift and specificity: Evidence from ko-phrases in Hindi. In Papers from the 32nd regional meeting of the Chicago Linguistics Society, 11-22. Chicago: Linguistics Society.

Bibis, Nick, and Yves Roberge. 2004. Marginal clitics. Lingua 114(8): 1015-1034.

Bittner, Maria, and Ken Hale. 1996. The structural determination of case and agreement. Linguistic Inquiry 27(1): 1-68.

Bobaljik, Jonathan David. 2008. Where's phi? Agreement as a post-syntactic operation. In Phi theory: Phi-features across interfaces and modules, eds. Daniel Harbour, David Adger, and Susana Béjar, 295-328. Oxford: Oxford University Press.

Bobaljik, Jonathan David, and Susi Wurmbrand. 2008. Case in GB/minimalism. In The Oxford handbook of case, eds. Andrej Malchukov and Andrew Spencer, 44-58. Oxford: Oxford University Press.

Bobaljik, Jonathan David, and Susi Wurmbrand. 2013. Suspension across domains. Distributed Morphology Today: Morphemes for Morris Halle, 185-198.

Bonet, Eulalia. 1991. Morphology after syntax: Pronominal clitics in Romance. Cambridge: MIT Press.

Borer, Hagit. 2003. Exo-skeletal vs. endo-skeletal explanations: Syntactic projections and the lexicon. In The nature of explanation in linguistic theory, 31-67.

Borer, Hagit. 2005a. Structuring sense I: In name only. Oxford: Oxford University Press.

Borer, Hagit. 2005b. Structuring sense II: The normal course of events. Oxford: Oxford University Press. Bortone, Pietro. 2010. Greek prepositions: From antiquity to present. Oxford: Oxford University Press.

Bosse, Solveig, Benjamin Bruening, and Masahiro Yamada. 2012. Affected experiencers. Natural Language and Linguistic Theory 30(4): 1185-1230.

Bossong, Georg. 1985. Empirische Universalienforschung: Differentielle Objectmarkierung in den Neuiranischen Sprachen. Tübingen: Gunter Narr Verlag.

Bossong, Georg. 1991. Differential object marking in Romance and beyond. New analyses in Romance linguistics, 143-170.

Bruening, Benjamin. 2010. Ditransitive asymmetries and a theory of idiom formation. Linguistic Inquiry 41(4): 519-562.

Bruening, Benjamin. 2014. Word formation is syntactic: Adjectival passives in English. Natural Language and Linguistic Theory 32(2): 363-422.

Burzio, Luigi. 1986. Italian syntax: A government-binding approach. Dordrecht: Springer.

Caha, Pavel. 2009. The nanosyntax of case. PhD diss., University of Trømso.

Chomsky, Noam. 1981. Lectures on government and binding. Dordrecht: Foris.

Chomsky, Noam. 1986. Knowledge of language: Its nature, origin, and use. New York: Praeger.

Deal, Amy Rose. 2013. Possessor raising. Linguistic Inquiry 44(3): 391-432.

den Dikken, Marcel. 2007. Phase extension: Contours of a theory of the role of head movement in phrasal extraction. Theoretical Linguistics 33(1): 1-41. 
Dimitriadis, Alexis. 1999. On clitics, prepositions and case licensing in Standard and Macedonian Greek. In Studies in Greek syntax, 95-112. Dordrecht: Springer.

Doron, Edit, ed. 2014. Theoretical Linguistics 40 (3/4), Special issue on the Identity of Roots.

Folli, Raffaella, and Heidi Harley. 2004. Consuming results: Flavors of little-v. In Aspectual enquiries, eds. Tungseth Mai, Paula Kempchinsky, and Roumyana Slabakova, 95-120. Dordrecht: Springer.

Folli, Raffaella, and Heidi Harley. 2007. Causation, obligation, and argument structure: On the nature of little v. Linguistic Inquiry 38(2): 197-238.

Gallego, Ángel J. 2006. Phase sliding. Ms., Autonomous University of Barcelona and University of Maryland.

Gallego, Ángel J. 2010. Phase theory. Amsterdam: Benjamins.

Gallego, Ángel J., and Juan Uriagereka. 2006. Sub-extraction from subjects. Ms., Autonomous University of Barcelona and University of Maryland.

Georgala, Effi. 2012. Applicatives in their structural and thematic function: A minimalist account of multitransitivity. PhD diss., Cornell University.

Giusti, Guiliana, and Melita Stavrou. 2008. Possessive Clitics in the DP: Doubling or dislocation? In Clitic doubling in the Balkan languages, eds. D. Kallulli and L. Tasmowski, 389-433. Amsterdam: Benjamins.

Grestenberger, Laura. 2017. Deponency as reanalysis: A diachronic account of voice mismatches. Ms., Concordia University/University of Vienna.

Grimm, Scott. 2007. Case attraction in ancient Greek. In 6th International Tblisi Symposium on Language, Logic and Computation (TbiLLC): Lecture notes in computer science, eds. Balder ten Cate and Henk Zeevat, 139-153. Berlin: Springer.

Groos, Anneke, and Henk van Riemsdjik. 1981. Matching effects in free relatives: a parameter of core grammar. In The theory of markedness in generative grammar, eds. Adriana Beletti, Luciana Brandi, and Luigi Rizzi, 171-216. Pisa: Scuola Normale Superiore di Pisa.

Grosu, Alexander. 1994. Three studies in locality and case. London: Routledge.

Harley, Heidi. 1995. Subjects, events and licensing. PhD diss., MIT.

Harley, Heidi. 2014. On the identity of roots. Theoretical Linguistics 40(3-4): 225-276.

Harley, Heidi, Mercedes Tubino, and Jason D. Haugen. 2016. Locality conditions on suppletive verbs in Hiaki. In The morphosyntax-phonology connection: Locality and directionality at the interface, eds. Vera Gribanova and Stephanie Shih. Oxford: OUP.

Haspelmath, Martin. 1994. Passive participles across languages. Voice: Form and function 27.

Hole, Daniel. 2005. Reconciling "possessor" datives and "beneficiary" datives: Towards a unified voice account of dative binding in German. In Event arguments: Foundations and applications, eds. Claudia Maienborn and Angelika Wöllstein 213-242. Tübingen: Niemeyer.

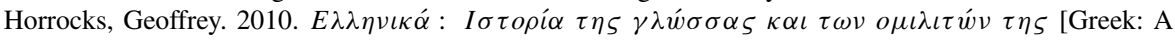
history of the language and its speakers]. London: Estia.

Humbert, Jean. 1930. La disparition du datif en grec du Ièr au Xèm siècle. Paris: Champion.

Humbert, Jean. 1960. Syntaxe grecque. Paris: Klincksieck.

Kalin, Laura, and Philipp Weisser. 2019. Asymmetric DOM in coordination: A problem for movementbased approaches. Linguistic Inquiry 50(3): 662-676.

Kakarikos, Konstantinos. 2014. Major trends in theoretical and applied linguistics 1: Selected papers from the 20th ISTAL, eds. Nikolaos Lavidas, Thomai Alexiou and Areti Maria Sougari, 298-304. Berlin: de Gruyter.

Kayne, Richard. 1975. French syntax: The transformational cycle. Cambridge: MIT Press.

Keine, Stefan. 2016. Probes and their horizons. PhD diss., University of Massachusetts, Amherst.

Kotzoglou, George, and Dimitra Papangeli. 2007. Not really ECM, not exactly control: The 'quasi-ECM' construction in Greek. In New horizons in the analysis of control and raising, 111-131. Dordrecht: Springer.

Kratzer, Angelika. 1996. Severing the external argument from its verb. In Phrase structure and the lexicon, 109-137. Dordrecht: Springer.

Landau, Idan. 1999. Possessor raising and the structure of VP. Lingua 107: 1-37.

Landau, Idan. 2010. The explicit syntax of implicit arguments. Linguistic Inquiry 41(3): 357-388.

Larson, Richard K. 1988. On the double object construction. Linguistic inquiry 19(3): 335-391.

Lee-Schoenfeld, Vera. 2012. Case and affectedness in German inalienable possession constructions. In Tampa papers in linguistics Vol. 2, eds. Stefan Huber and Sonia Ramírez Wohlmuth, 65-79.

Leivada, Evelina, and Kleanthes K. Grohmann. 2014. Clitics in idioms: Properties of morphosyntax and reference. Lingua 150: 45-70. 
Levin, Beth. 1993. English verb classes and alternations. Chicago: The University of Chicago Press.

Levin, Beth. 2006. English object alternations: A unified account. Ms., Stanford, 7-36.

Levin, Beth. 2012. Slap, give a slap, slap a slap: Crosslinguistic diversity in hitting event descriptions. In Tenth biennial conference of the High Desert Linguistics Society, University of New Mexico.

Levin, Beth, and Malka Rappaport. 1986. The formation of adjectival passives. Linguistic Inquiry 17(4): 623-661.

Levin, Theodore, and Omer Preminger. 2015. Case in Sakha: Are two modalities really necessary? Natural Language and Linguistic Theory 33(1): 231-250.

Lidz, Jeffrey. 2006. The grammar of accusative case in Kannada. Language 82: 1-32.

Lohndal, Terje. 2014. Phrase structure and argument structure: A case study of the syntax-semantics interface. Oxford: Oxford University Press.

Luraghi, Silvia. 2003. On the meaning of prepositions and cases: The expression of semantic roles in Ancient Greek. Amsterdam: Benjamins.

Luraghi, Silvia. 2010. The extension of the transitive construction in Ancient Greek. Acta Linguistica Hafniensia 42(1): 60-74.

Mackridge, Peter. 1985. The modern Greek language: A descriptive analysis of standard Modern Greek. New York: Oxford University Press.

Mackridge, Peter. 2009. Language and national identity in Greece, 1766-1976. Oxford: Oxford University Press.

Marantz, Alec. 1991. Case and licensing, Vol. 8 of Eastern States Conference on Linguistics (ESCOL'91), 234-253.

Marantz, Alec. 1993. Implications of asymmetries in double object constructions. Theoretical aspects of Bantu grammar 1: 113-151.

Marantz, Alec. 1997. No escape from syntax: Don't try morphological analysis in the privacy of your own lexicon. University of Pennsylvania working papers in linguistics 4(2): 14.

Masica, Colin P. 1976. Defining a linguistic area: South Asia. Chicago: The University of Chicago Press.

McFadden, Thomas. 2004. The position of morphological case in the derivation: A study on the syntaxmorphology interface. PhD diss., University of Pennsylvania.

Mertyris, Dionysios. 2014. The loss of the genitive in Greek: A diachronic and dialectological analysis. PhD diss., La Trobe University.

Michelioudakis, Dimitris, and Eleni Kapogianni. 2013. Ethical datives: A puzzle for syntax, semantics, pragmatics, and their interfaces. In Syntax and its limits, eds. Raffaella Folli, Christina Sevdali, and Robert Truswell, 345-369. Oxford: Oxford University Press.

Michelioudakis, Dimitris. 2012. Dative arguments and abstract Case in Greek. PhD diss., University of Cambridge.

Miyagawa, Shigeru. 2001. The EPP, scrambling, and wh-in-situ. Current Studies in Linguistics Series 36: 293-338.

Næss, Åshild. 2011. The grammar of eating and drinking verbs. Language and Linguistics Compass 5(6): 413-423.

Nevins, Andrew Ira. 2007. The representation of third person and its consequences for person-case effects. Natural Language and Linguistic Theory 25(2): 273-313.

Newman, John, ed. 2009. A cross-linguistic overview of 'eat' and 'drink'. The linguistics of eating and drinking, Vol. 84 of Typological Studies in Language, 1-26. Amsterdam: Benjamins.

Oikonomou, Despina. 2011. Voice and argument structure: Deponent verbs in Greek. Ms., MIT.

Oikonomou, Despina. 2014. The middle of passive: middle voice in modern greek vs. passive voice in English. Ms., MIT. Available at https://despinaoikonomou.files.wordpress.com/2018/11/in-themiddle-of-passive_generals-paper.pdf. Accessed 27 January 2020.

Pesetsky, David. 1995. Zero syntax: Experiencers and cascades. Cambridge: MIT Press.

Pesetsky, David. 2013. Russian case morphology and the syntactic categories. Cambridge: MIT Press.

Pesetsky, David, and Esther Torrego. 2011. Case. The Oxford handbook of linguistic minimalism, ed. Cedric Boeckx, 52-72. Oxford: Oxford University Press.

Polinsky, Maria. 2016. Deconstructing ergativity: Two types of ergative languages and their features. Oxford: Oxford University Press.

Preminger, Omer. 2014. Agreement and its failures. Cambridge: MIT Press.

Probert, Philomen. 2015. Early Greek relative clauses. Oxford: Oxford University Press.

Pylkkänen, Liina. 2002. Introducing arguments, Ph.D. dissertation, MIT.

Pylkkänen, Liina. 2008. Introducing arguments. Cambridge: MIT Press.

Rezac, Milan. 2008. Phi-agree and theta-related case. In Phi theory: Phi-features across modules and interfaces, eds. Daniel Harbour, David Adger, and Susana Béjar. Oxford: Oxford University Press. 
Richards, Norvin. 2013. Lardil "case stacking” and the timing of case assignment. Syntax 16(1): 42-76.

Schäfer, Florian. 2008. The syntax of (anti-)causatives: External arguments in change-of-state contexts. Amsterdam: Benjamins.

Schütze, Carlson. 1997. INFL in child and adult language: Case, agreement and licensing. PhD diss., MIT.

Schütze, Carlson. 2001. On the nature of default case. Syntax 4: 205-238.

Schwyzer, Eduard, and Albert Debrunner. 1950. Griechische Grammatik II. Syntax und syntaktische Stilistik, München: Beck.

Sevdali, Christina. 2007. Infinitival clauses in Ancient Greek: Overt and null subjects, the role of Case and focus. PhD diss., University of Cambridge.

Sigurðsson, Halldór Ármann. 2004. Icelandic non-nominative subjects: Facts and implications. In Nonnominative subjects, Vol. 2, eds. Peri Bhaskararao and Karumuri Subbarao, 137-159. Amsterdam: Benjamins.

Smyth, Herbert Weir. 1956. Greek Grammar. Cambridge: Harvard University Press.

Terzi, Arhonto. 2008. Locative Prepositions as Modifiers of an Unpronounced Noun. In West Coast Conference on Formal Linguistics (WCCFL) 26, eds. Charles B. Chang and Hannah J. Haynie, 471-479. Somerville: Cascadilla Proceedings Project.

Terzi, Arhonto. 2010. Locative prepositions and Place. In Mapping spatial PPs: The cartography of syntactic structures, Vol. 6, eds. Guglielmo Cinque and Luigi Rizzi, 196-224. Oxford: Oxford University Press.

Vergnaud, Jean-Roger. 2008. Letter to Noam Chomsky and Howard Lasnik on 'Filters and Control, April 17, 1977'. In Foundational issues in linguistic theory, eds. Robert Freidin, Carlos Otero, and MariaLuisa Zubizaretta, 3-5. Cambridge: MIT Press.

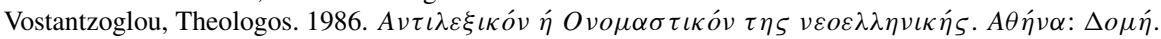

Woolford, Ellen. 2006. Lexical case, inherent case, and argument structure. Linguistic Inquiry 37(1): 111130.

Yip, Moira, Joan Maling, and Ray Jackendoff. 1987. Case in tiers. Language 63(2): 217-250.

Zaenen, Annie, Joan Maling, and Höskaldur Thráinsson. 1985. Case and grammatical functions: The Icelandic passive. Natural Language and Linguistic Theory 3(4): 441-483.

Zombolou, Katerina, and Artemis Alexiadou. 2014. Deponents in Greek: Losing and creating active voice counterparts. Paper presented at Workshop "Voice Systems in Diachrony: A Comparative Perspective", Pavia. 